\title{
ISTVÁN SZŐKÖL
}

\section{EDUCATIONAL}

\section{EVALUATION}

IN CONTEMPORARY SCHOOLS

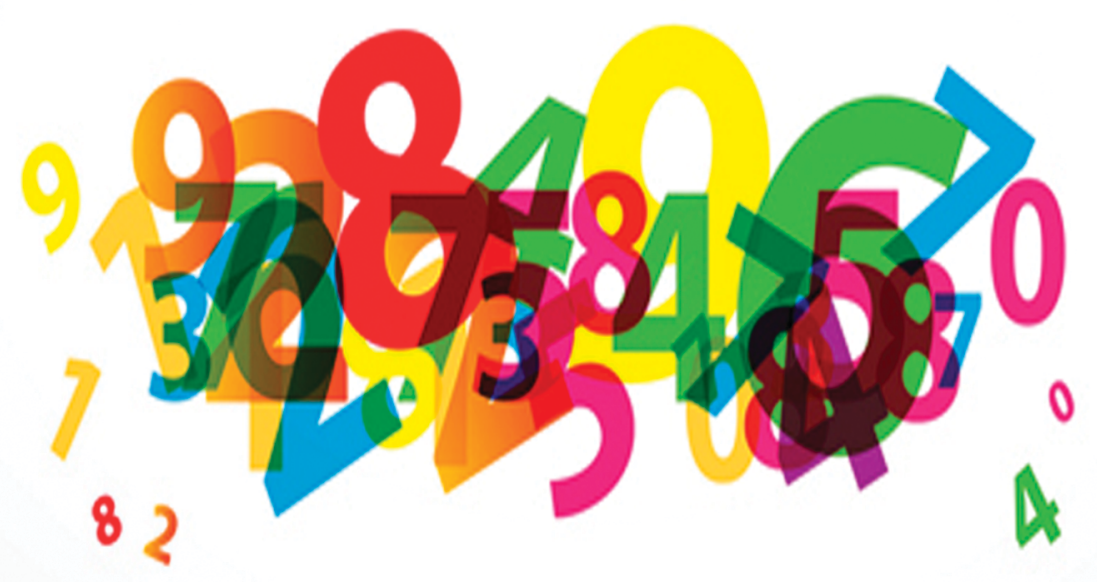




\section{EDUCATIONAL EVALUATION IN CONTEMPORARY SCHOOLS}





\section{István Szőköl}

\section{EDUCATIONAL EVALUATION \\ IN CONTEMPORARY SCHOOLS}


Educational Evaluation in Conterporary Schools

\author{
Reviewers \\ Prof. Dr. Jenő Bárdos, DSc. \\ Dr. h.c. Prof. Ing. Albert Sándor, PhD.
}

Language Reviewer

PaedDr. Puskás Andrea, PhD.

\title{
Boritóterv
}

Andrea Majzik

The book was written in the framework of KEGA grant project "Internacionalizácia ŠP predškolská a elementárna pedagogika pre II. stupeň VŠ štúdia” (005UJS-4/2015).

ISBN 978-615-5372-60-5 (print)

ISBN 978-615-5372-61-2 (online pdf)

(C) Dr. habil. Ing. István Szőköl, PhD., 2016

(C) J. Selye University, Komárno, 2016

(C) Belvedere Meridionale, 2016 
For András and Márton 



\section{CONTENT}

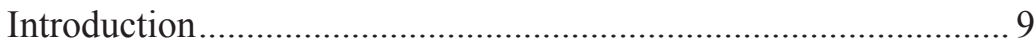

1 Control and Evaluation in Teaching - Definition of Terms ....... 15

1.1 Specifics of educational evaluation........................................ 21

2 The qualitative transformation of understanding the essence of the education process and learning ......................................... 28

2.1. The concepts of the education process.................................. 36

2.2 The teacher's personality in relation to the educational

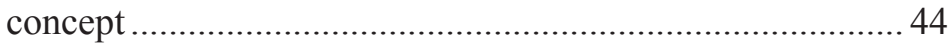

2.2.1 Behaviorally oriented individual educational concept......49

2.2.2 Human-oriented individual educational concept ........... 50

2.2.3 Socio-cognitive, cognitive-oriented individual educational method ........................................................ 52

3 The concepts, functions and dimensions of educational

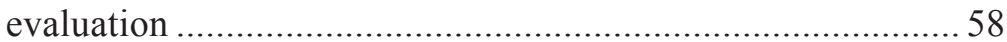

3.1. The concepts of evaluation in relation to the concepts of

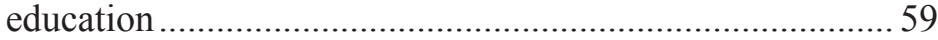

3.1.1 The concept of competition in educational evaluation .......59

3.1.2 The concept of non-competition in educational

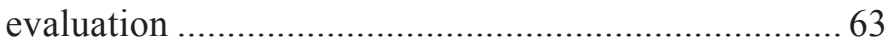

3.1.3 The cooperative concept of educational evaluation....... 65

3.1.4 The humanistic-oriented concept of educational

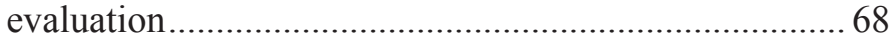

3.1.5 The development concept of educational evaluation..... 69

3.2 The functions of educational evaluation ................................ 71

3.2.1 The development-formative function of educational

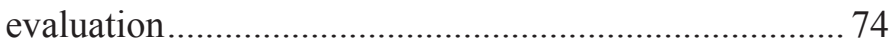

3.2.2 Educational evaluation in the function of feedback ...... 80

3.2.3 The informative function of educational evaluation....... 81 
3.2.4 The function of greater efficiency in educational

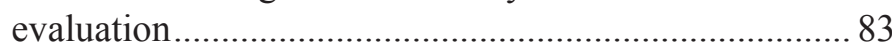

3.2.5 The differential and selective function of educational

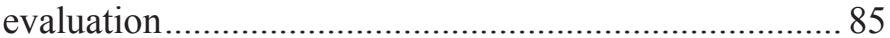

3.2.6 The teacher's attitude to students and the methods of evaluation

3.3 The dimensions of educational evaluation............................90

3.3.1 The social and personality dimensions of educational

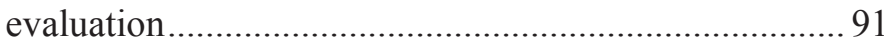

3.3.2 The didactic dimension of educational evaluation ........93

3.3.3 The social dimension of educational evaluation............ 93

3.4 New methods of testing and evaluation.................................99

3.5 Authentic teaching and evaluation ........................................ 98

4 Categories of educational evaluation ......................................... 103

4.1 The process, methods and forms of educational evaluation.... 112

4.1.1 The stage of setting goals, planning and the organization of educational evaluation............................................. 116

4.1.2 Information gathering stage, the choice of methods, instruments, tools to assess the phenomenon of educational reality ......................................................... 116

4.1.3 The stage of evaluating and interpreting results .......... 137

4.1.4 The decision phase of the prediction draft................... 142

4.2 The rules and criteria of educational evaluation................. 142

4.3 The micro level of educational evaluation - the state of researched problems........................................................... 145

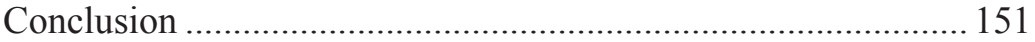

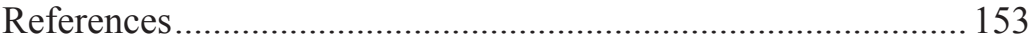




\section{INTRODUCTION}

In recent years, our education system has undergone major changes and has been influenced by the ideas of various educational guidelines, which come from abroad. Due to the rapid development of society the approach to education is changing too. The information explosion causes that the main mission of the school ceases to be transferring information to students. Graduates have to take more permanent values from school than knowledge - attitudes, interests, motivation, value system, accomplished abilities and skills.

The school ceases to be the main source of knowledge. Every day we get a lot of information from the media and the Internet. The school is unable to convey all this knowledge to students. Its main task becomes to teach students how to search for knowledge, process and apply it in practice. This is the only way to have creative young people who are able to think on their own, solve problems and also who are confident and balanced enough to be successful.

The shortcomings of the traditional evaluation of students in schools include not respecting the qualities of students, suggesting blocking mechanisms, the lack of harmony between educational requirements and what students themselves consider necessary, the reduction of interpersonal values (signs of cooperation whisperings - are punished), reducing creativity (the teacher expects students to learn things by heart), intolerance to individual variations (there is not enough attention paid to talented and weaker students, the teacher teaches on the basis of what the average level of performance in the class is), the interaction between the teacher and the students (there is no partnership between them, teachers 
divide students into two categories, competent and incompetent ones).

One of the ways to make the school become a place with creative young people, who are able to think on their own, solve problems and are also confident and destined to succeed, is to change evaluation practices and the grading system. Many teachers have already changed their path to this direction by replacing the traditional marking system by verbal evaluation.

The education process is a complex process, which is characterized by the influence that the teachers' actions have on the students' action and vice versa and also by the cooperation between teachers and students and adaptation. The education process currently does not consider the teacher the only means of transferring knowledge to students but by engaging them in the education process they will acquire a more active approach to obtain knowledge and new skills. Knowledge, abilities and practical skills acquired by students will significantly help them in building their future professional life.

Without an extensive, objective and reliable evaluation of students' performance, the Slovak educational system cannot solve the key challenges that it is facing: a substantial increase of the quality of education, the democratization and humanization of education, the effective management of education, the achievement of the objectives necessary for the development of our society in the 21 st century such as the development of creative skills, the ability to learn and adapt flexibly to the rapidly changing conditions of life, the development of emotional sphere of citizens, etc. These are the reasons that motivated me to write this publication.

Evaluation in someone's life plays different roles depending particularly on the aim, object and subject of the evaluation as 
well as the environment and conditions. Evaluation in school is a prerequisite for the teacher's successful and effective work. Checking the education process consists of measuring the results (examination resp. testing), and evaluating them (evaluation - comparing knowledge, skills, attitudes with some concrete requirements - curriculum, performance standards, learning outcomes). Evaluation includes the grading system too, i.e. having different categories on the basis of performance (mark, number, percentage, portfolio, etc.).

Evaluation should not only focus on the result but also on the process of cognitive activities. Without this evaluation cannot fulfil all the functions, as for example controlling, prognostic, motivational, educational, informational, evolving, the function of providing feedback and more.

Teachers who realize the potential functions of evaluation for the development of students' personality understand the essence of evaluation functions, respect them and use them effectively. Evaluation can encourage students in a positive way for further work, or, conversely discourage them totally. Up to what degree is the teacher able to influence students with evaluation depends on how deeply he knows his students, respects their values and priorities.

Although significant attention in the monograph is devoted to students' educational evaluation by their teachers (which we consider a micro evaluation), which may also be conceived as a didactic dimension of my main issues, I considered it important to pay special attention to the meso and macro level of evaluation too. My aim was to move the issue of evaluation in the educational process to a wider context, and strengthen the school management dimension of this particular problem. 
The monograph Educational evaluation in contemporary schools is divided into four chapters. Each chapter contains a concise summary with information about the content of the particular chapter. All four chapters focus on micro-evaluation.

The first chapter offers a view of the controlling process and evaluation as part of the management process with particular reference to one of its part - the education process. First of all, I provide a definition of the controlling process in general and list its tasks and phases. I offer different views and definitions of control. There is a more detailed analysis of control in the education process, which consists of two interconnected and dependent tasks. The first is to obtain information about the results of the education process, so it focuses on student performance and the level of the achievement of goals. The second is to evaluate the results of the education process. This is referred to as student evaluation. I also define the concept of evaluation in general as well list the specifics of educational evaluation. The definition of the specifics of educational evaluation is of great importance in terms of the structure and content of the monograph because each of them will be discussed separately in the coming chapters.

Educational evaluation takes place mainly within the education process, and for this reason the second chapter focuses on this process. I point out that the education process which is intentionally controlled is a systematic and organized process between teachers and learners in the social environment of the school in which a sequence of cognitive, learning-oriented operations and noncognitive actions aimed at social and personal education in real or simulated situations take place. It is also affected by the conditions in which it happens. Apart from this, external conditions which represent the character of socio-historical, cultural, political and 
social context also have an influence on how the nature of the education process is viewed. This factor is analysed in the part called 'The concepts of the education process'. Internal conditions of the education process are those characteristic traits of the subject and object, which they take into the process and which later become the object of their development. In this respect, the aim is to focus on the teacher's personality, and I will follow a paradigm change in their acceptance, depending on the concept of teaching. There is more on this topic in part 'The teacher's personality in relation to the concept of teaching'.

How the view on evaluation in the education process changes according to the concepts of teaching, is what the third chapter, 'The concepts, features and dimensions of educational evaluation' focuses on. I identify five current concepts of educational evaluation: the competitive concept of educational evaluation, non-competitive concept of educational evaluation as well as the co-operative concept of educational evaluation and based on domestic literature I will discuss the humanistic oriented approach and the evolving concept of educational evaluation. Furthermore, I will characterize the different functions of educational evaluation, which emerged gradually as the demand for evaluation grew. I offer inspiring classification of the evaluation function according to the purpose they serve: emerging-formative function, a function ensuring feedback, an informing function, a function ensuring greater efficiency or a differentiating function. By defining the functions of educational evaluation my intention is to get to the dimensions of educational evaluation which I consider important because they provide a more plastic picture of the process, means and methods that can be applied in educational evaluation. From this perspective, I intend to examine in details the personal and 
social dimension as well as the didactic and social dimension of educational evaluation.

The fourth chapter 'The types of educational evaluation' focuses on the pros and cons of different types of educational evaluation and their impact on the development of students' personality. I emphasize the fact that different types of evaluations differ from each other not only by their informational value, but also by the motivational consequences that arise from the information. In this chapter I intend to introduce the methods and forms of educational evaluation in relation to the different stages of the evaluation process. In order to make the evaluation efficient, to fulfil their functions and, last but not least, to make it a means of shaping the students' personality, it is necessary to stress another aspect and that is the importance of having clear rules of the evaluation set in advance. This can also help to make the evaluation more objective. In the third subsection, which is called 'The microlevel of educational evaluation' - the condition of the examined problem, I present several studies on the evaluation of today's schools and their results in terms of classes and students.

Since educational evaluation is such a broad issue in my publication it was impossible to examine it from every possible aspect. I will be grateful to the readers for their critical comments and suggestions aimed at improving this work.

I recommend this publication to everybody who is involved in student evaluation, directly or indirectly.

I would like to express my sincere gratitude to prof. Dr. Jenő Bárdos, DSc. and Dr. h.c. Prof. Ing. Sándor Albert, PhD. for their professional help, support and guidance they have provided throughout my work. 


\section{CONTROL AND EVALUATION IN TEACHING - DEFINITION OF TERMS}

Traditional pedagogy is based on the structure of the education process, which indicates that the student is not a passive object, but an active subject, and that between the teacher and students a transfer of information (giving - receiving) and feedback takes place.

As reported by I. Turek $(1996,4)$, "Examining, testing is a process aimed at obtaining information about what a student knows and does not know and to what extent he knows what he should". Examining how the objective of the education process has been achieved, must be assessed, so in the future, or more precisely on the coming lessons students will be aware of the degree to which they have acquired knowledge and skills and the teacher, on the other hand, will see whether the chosen teaching method was the right one. On the basis of the information he gains, he will have a chance to decide on how to proceed. This activity is called evaluation. I. Turek (1996, 4) states that "evaluation is expressing a conclusion, i.e. evaluating the results of the teaching process". Evaluation is an activity which focuses on comparing some features of both people and objects with criteria defined in advance. Evaluation is the most important and most frequent category of pedagogical diagnosis. Questions related to evaluation are currently one of the most debated topics, both in theory and practice and also among the general public. Evaluation is crucial in terms of creating the theory of pedagogical diagnosis, as well as its corresponding practice.

Evaluation is a process which focuses on evaluating a particular activity, phenomenon, situation, action and behaviour through verbal and nonverbal means. This is a broad area of short and 
long-term activities of teachers such as examining, testing, controlling, and evaluating students. The result of these activities is student evaluation, respectively the evaluation of a class or groups in various forms. Although in practice the terms evaluation and classification seem interchangeable, it is important to realize that these terms are not equivalent, evaluation is a broader term and it includes classification too, which is the result of the evaluation process. However, classification is not the only result of this process.

How students should be evaluated and marked in the practice of education, so that the practice and the education process has its meaning and meet the expectations depends on several criteria; the students' level of theoretical knowledge as well as the working environment within the practice or the presentation skills of teachers that they need to pass on to students the theoretical knowledge are all to be taken into consideration. Finally, evaluation in the practice of education should meet the evolving feature, noting the development of the student, his motivation since it should help him to focus on his possibilities.

Evaluation in the practice of education has three components:

- quantitative, which gives information about the number of tasks that students were able to solve and put into practice,

- qualitative, the essence of which is a general summary of the students' ability to solve a specific task by putting the knowledge that they have obtained into practice,

- value judgment that allows the teacher to see improvement (or worsening) of the students' knowledge and their practical skills.

Student evaluation in the education process is closely related to diagnosing, that is identifying and assessing the students' level 
of knowledge, skills and abilities. Getting to know students can result in a more positive approach to learning on their part and consequently acquiring new knowledge.

Since the internal evaluation mechanisms serve as an engine of development in every social organization and are, therefore, of great importance, it is essential that they are seen in a mutual complementary relationship with controlling processes. For this reason, this chapter will take a closer look at the controlling process and evaluation as parts of the management process, with a particular emphasis on the education process. First, I define the controlling process in general and then list its tasks and stages. I offer different approaches and definitions of control. After the general characteristics and conceptual definitions, a closer look will be taken at the control of the education process, which consists of two interdependent tasks. The first one is the identification of the results of the education process, which is a measurement of student performance and the degree up to which the goals of the education process have been met. The second one is the evaluation of the results of the education process, which is called student evaluation. I define evaluation in general and finally some specifics of educational evaluation will be discussed, which- in terms of this monograph's structure and content - is of great importance because in the following chapters, each of them will be discussed separately.

Control and evaluation are closely related, however, they are not the same phenomena. Control, as part of the management process is defined as a factor of balance between the desired and the actual state (Horváthová-Szőköl, 2013, 8). Control cannot, therefore, be viewed as a formal function of the management process. In management it has a more important position, because 
it is the factor that we use to ensure the quality and development of schools as a whole. This also applies to the quality of the education process, which in fact is the crucial process in the whole system of educational management. This is explained by the fact that by controlling, the results of the education process are being identified and assessed, what students have learned, mastered in the cognitive, affective and psychomotor area (Turek 2008, 339).

Control is usually performed in order to assess the level of the followed (controlled) phenomena, and the aim of the controlling processes is to get a so called verdict from the evaluation court. The task of control is to identify the actual development of the controlled object as well as the final status, to identify any possible deviations from the plan and their causes and to draw conclusions for further decisions. The aim of control is its positive impact on better results, improvement of processes, development of the organization and the students themselves too.

In the controlling process there are some phases (Sedlák 1998, 159) that represent the different stages, respectively activities arranged in a time sequence. The basic controlling process consists of partial phases or steps:

- drawing up a set of standards that are expressed in money, in natural or quality units, or any combination thereof; for each form of expression first the indicator is selected and then the extent is determined.

- measuring the actual performance most of the time takes place in the form of personal observation;

- evaluating the actual performance by comparing it to the standard. In this case two things can happen - the performance is either in harmony with the standard or it is not. In case of the latter the deviation from the standard needs to be identified and after this 
the performance standard has to be examined and reassessed and in accordance with the terms readjusted.

- correcting is an important part of the controlling process, which monitors the implementation of the appropriate corrective measures in the operation.

There are various definitions and understanding of control. The information-based concept of control proceeds from its cybernetic interpretation which considers it a feedback between the subject and the object and it begins with ascertaining facts and confronting the anticipated situation (goals, objectives) and ends with identifying the deviation and providing the necessary information. The regulatory concept of control is a wider notion than the information concept since it expects cooperation in order to remove unwanted drifts. The repressive concept considers control a factor that reveals the shortcomings and violations which need to be punished and repression needs to be carried out. The institutional concept considers control a specialized activity of individual control bodies that have no direct responsibility for leadership and it claims that only managers have the possibility to remedy. The democratic concept of control is based on minimizing external direction and control, strengthening internal control, self-control, on the relations of cooperation and the efficiency of the subject and object as well as the connectivity of the internal and external control systems (Horváthová - Szököl, 2013, 11).

The control of the education process consists of two interdependent tasks (Turek 2008, 339). The first is to identify the results of the education process, which is the measurement of student performance and the degree up to which the goals of 
the teaching process have been met. The second is to evaluate the results of the education process that we call student evaluation.

Overall, evaluation means identifying, comparing, assessing the values of a phenomenon of the objective reality on the basis of its characteristics according to predefined standards, indicators or criteria (Horvathová- Szököl, 2013, 11). In addition to this, Kolar and Šikulová $(2009,11)$ say that evaluation is an appraisal of a phenomenon on the basis of the profound knowledge that has been obtained from it, on the basis of any analysis of this phenomenon and understanding how this particular phenomenon in certain situations works.

Evaluation is seen as an organic part of every human action, together with the decision-making process. Life is about constant decision-making whether it is a completely trivial thing or important situation. Every decision contains the processes of evaluation too - evaluating the abilities, situations, phenomenon and specific conditions. We make a final decision based on value judgment, analysis and the hierarchy of the acquired and declared values (Kolár-Šikulová 2009, 13). Thus, evaluation is an organic part of any purposeful human activity. Educational work can be considered such an activity, since its goal is an intentional, purposeful influence and personality development of a human being "however, the fact that the necessary knowledge and skills are the result and the process of coping with the knowledge and skills is the means of general and specific personality development of all students, needs to be pointed out." (Horvathová- Szőköl, 2013, 14). Evaluation is, therefore, an organic part of the education process, when not only the results achieved (compared with targets) are evaluated, but also the very process through which the goals and results have been achieved. The main participants 
of the education process, the teacher and the students, are also part of these evaluation processes.

\subsection{SPECIFICS OF EDUCATIONAL EVALUATION}

Ralph W. Tyler (1902-1994) was among the first ones to emphasize the importance and significance of evaluation in education. He assumed (according to Golnhofer 2003) that evaluation provides information about the level and degree up to which the objectives set in advance have been achieved. He constructed the evaluation model, which is dominated by three elements and their relations: goals which are the results manifested in the acquired knowledge, skills, habits, attitudes expected from students, students' experience and the very assessment which is to reveal whether the set objectives have been achieved or not. In this threecomponent model, Tyler credited the category of objectives with great importance. He claimed that the objectives need to be set in such a way that they contain clear criteria for student performance, respectively the necessary means and processes to perform. He emphasized that evaluation covers the whole education process.

Under the influence of theory systems and cybernetics, Tyler's model was enriched with new understanding, especially the search for the connection between the objectives, processes and accomplishment. The clarification of feedback as a principle of binding and regulation had an extremely positive impact on improving the process of innovation and increasing quality (Horvathova-Manniová 2008, 36-37). From a didactic and an educational point of view it presupposes the existence of such practices that make better use of evaluation to optimize the 
process of teaching. In this sense, evaluation is not only a part of the education process, but it is considered the system-creatingelement of the overall school management.

Evaluation in education certainly includes student performance or the level of the achievement of certain competencies. This understanding is reflected in the definition of educational evaluation that Petlák $(2004,96)$ define as a systematic process that leads to determine the quality and performance shown by the students, groups of students or educational programs. Although it may seem that this understanding is too narrow and reveals specifics on the level of individuals, classes or schools at the most, it is beneficial in that it is a concrete effort to highlight the trend aiming at increasing the quality of the education process. And it is not a matter of just one institution, but the whole system, even the whole society. In general, evaluation distinguishes three levels - macro, meso and micro level. On macro level the focus is on evaluating the results of the entire education system, often for international comparison. Most of the time it is carried out by an external (research) organization.

Meso level aims at evaluating the results of the education process. It is mostly observed within the school and is initiated by the director or sometimes an external organization. On micro level the education process and its outcomes are analysed in terms of the students themselves or classes. It is carried out by the teacher. As we could see the subject of evaluation varies according to the level of evaluation. In the coming part my priority will be to focus on the issues of micro level evaluation processes.

Evaluation is of great significance in human life, so it is important to master it. Learning to evaluate means "to give students the opportunity and create the conditions in the education process 
to be able to take part in the evaluation activities that would enable them to gain the skills and criteria necessary for self-knowledge and self-assessment as well as the understanding and evaluation of others" (Kolar-Šikulová 2009, 14). In this context it is possible to perceive personality development as one of the principal functions of school, which is achieved by focusing on activities that aim at developing the personality in terms of positive self-creation, self-awareness, and self-respect. The condition for all this is a functioning and developed self-evaluating ability.

Kosová (1998) understands evaluation as a process where students can be compared:

- with the objective norm through the educational standards that have a specifically defined objective - standards, core curriculum and criteria for their evaluation.

- with an object, when the teacher more or less deliberately compares student performances,

- with a subjective standard, more precisely a measuring tool selected or respectively constructed by the teacher which depends on how demanding he is.

- with themselves, when the teacher considers the basis of evaluation the very level of students' development.

It is the last one of the above mentioned aspects that relies to the greatest extent on the potential of self-evaluation, the importance of which lies in the fact that students realize the importance and meaning of what and why to learn, the sense of exploring their possibilities and abilities, they develop a sense of determining the real objectives as well as an ability to recognize their hidden potentials and resources, the need for self-reflection on their own activities. It is the teacher's responsibility to put this process in 
motion for the students and foster it. It will only be efficient if the teacher together with the students work on it on every lesson.

Evaluation in teaching is a very complicated, complex work of the teacher and students, and it has its own specifics. What makes evaluation so specific is listed below:

- the environment in which it is performed and by this I mean the wider social, socio-cultural conditions in which teaching takes place and on which the understanding of the nature of the education process is based,

- the personality of the teacher and not only his concept of teaching (which largely influences the way a teacher teaches or organizes the teaching process) and its impact on student achievement, - the tasks that evaluation performs in the education process and also the dimensions of educational evaluation,

- the methods and forms of evaluation which are applied according to the particular stage of the evaluation process,

- having procedures and criteria for evaluation, educational standards that define what a student has to know, therefore imply what is to be evaluated - leads to identifying the level of knowledge, abilities, skill and attitudes that have been achieved.

In connection with student evaluation in the education process, it is necessary to point out educational diagnostics as a branch of science that deals with the issues of diagnosis in the educational environment, defines the subject, strategies, procedures and methods of diagnosis (e.g. structured and unstructured observation, interviewing, written or oral tests, questions in the test, questionnaires, etc.). Educational diagnosis takes place in schools or other educational institutions, but also in the family environment. Diagnosis can thus be defined as a set of activities that take place during diagnosing, starting with 
the intent to diagnose until conclusion is expressed. Educational diagnosis is extended to the student's family environment, within which are identified and assessed the conditions for the student's education, household items, parental care and other socio - family conditions that individually and in context as well affect the student's learning and his interest in it. Educational diagnosis helps the teacher to get a faster and deeper insight about his student, his knowledge capacity, what is encouraging and what is discouraging for him in terms of learning and testing. Diagnosing is a process planned and it provides the teacher with a kind of feedback on himself, the kind of teacher he is and the possibilities that he has in order to improve his teaching skills. The diagnostic information therefore benefits not only students but teachers as well. On the one hand, by diagnosing and the results obtained from it, the teacher informs students about the progress they have made, through which they learn some information about themselves and also they find out whether the teacher is happy with them. This diagnosis serves as an incentive for students. On the other hand, based on the diagnosis the teacher can plan the practical training so as to best suit the students and possibly even improve it, in order to provide students with information in the most efficient way. Based on the knowledge gained from the diagnosis, the teacher is able to choose an appropriate and correct form of evaluation in terms of practical education.

In the following sections of the monograph I will analyze each of the above mentioned aspects of educational evaluation separately. However, I will not lose sight of the fact that educational evaluation is also affected by other characteristics, in particular by:

- a systematic approach, which lies in the fact that the teacher spends time preparing for it, organizes and carries it out regularly and the results are compared with the chosen standards, 
- focusing on the goal when the teacher sets the aim of the evaluation in advance (it is possible to evaluate the cognitive qualities of students, the affective qualities, the social relationships between students and teachers, and by this I do not mean only the outputs, thus student performance, but the quality of the education process, which requires permanent feedback from the teacher and reflection on the process of student learning activities),

- the teacher's opportunity and ability to perceive the results of evaluation as a means of self-reflection on his own teaching activity (its quality).

\section{SUMMARY}

In the first chapter, which is called 'Control and Evaluation in Teaching - Definition of Terms', my intention was to provide a definition of the controlling process in general, particularly in terms of school management. Control in this sense acts as a factor in the balance between the desired and actual status. I defined the tasks and stages of the controlling process in general, and offered various concepts and definitions of control. The core processes, however, that take place in the school are the education processes which I characterized. The control of the education process consists of two interconnected and dependent tasks. The first is the identification of the results of education process, which is a measurement of student performance, the level of the achieved objectives. The second is the evaluation of the results of the education process, which is called student evaluation. The education process control consists of two interdependent tasks. The first is the identification of the results of the education process, which is the measurement 
of the student performance and the degree up to which the goals have been met. The second is the evaluation of the results, which is called student evaluation.

Idistinguished three levels of evaluation: macro, meso and micro level. On macro level the focus is on evaluating the results of the entire education system, often for international comparison. Most of the time it is carried out by an external (research) organization.

Meso level aims at evaluating the results of the education process. It is mostly observed within the school and is initiated by the director or sometimes an external organization. On micro level the education process and its outcomes are analysed in terms of the students themselves or classes. It is carried out by the teacher. I defined evaluation and also listed the specifics of educational evaluation. What makes evaluation specific is the environment, the personality of the teacher, the tasks that evaluation plays in the education process and also the dimensions of educational evaluation, the methods and forms which are applied according to the particular stage of the evaluation process as well as the rules and criteria for evaluation, the educational standards that define what a student has to know, therefore imply what is to be evaluated - leads to identifying the level of knowledge, abilities, skills and attitudes that have been achieved.

Defining the specifics of educational evaluation in terms of structure and content is the key moment of the monograph. The upcoming chapters of the monograph focus on the above-defined specifics of educational evaluation. 


\section{THE QUALITATIVE \\ TRANSFORMATION OF \\ UNDERSTANDING THE ESSENCE \\ OF THE EDUCATION PROCESS AND \\ LEARNING}

Educational evaluation is carried out mainly within the education process, so in the second chapter I will offer a deeper look into this process. In accordance with Manniová $(2008,10)$ I intend to point out that the education process is an intentionally controlled, systematic and organized process between the teacher and the learners in the social environment of the school, where a sequence of cognitive, learning-oriented operations and non-cognitive actions take place. They all aim at the social and personal education in real or simulated situations. The education process, its character and course, are also affected by the conditions in which it takes place. The conditions can be divided into external and internal conditions and this chapter of the monograph focuses on this topic. External conditions include not only the nature of socio-historical, cultural, political and social context, which have a great influence on how the education process is perceived, but also the effect of society on the student and teaching, the impact of mass media, the increasing living standards of families (Petlák 1997 60), school equipment, the activities of the school management, parental and other public inputs (Kolar-Vališová 2009, 7). The internal conditions of the education process are those personality traits of the subject and object of the process that they have when entering the education process and which later become the focus of their development (See also Jancsák 2013). Therefore, according to Kolar and 
Vališová (2009: 7) it is also necessary to take into account the personalities of the two main factors - motivation, characteristic features, intelligence, moral qualities, the interests of teachers and students.

Petlák E. $(2004,24)$ assumes that "didactics is the science of the education process in its focus." About the education process we can say that it is a highly complex and demanding process between students and teachers. Didactics as the most sophisticated pedagogical discipline in the context of the education process deals mainly with the education process itself. The education process is the process of acquiring new knowledge, skills and habits.

The concept of the education process can be defined as a planned, purposeful and deliberate action carried out by the teacher and it is aimed at the student so that he is systematically educated. The object of education and training (student) is also the subject of the teaching process, because in addition to acquiring new knowledge, capabilities, skills and developing some habits and cognitive processes that shape his personality, he influences the teacher's activities (Jancsák 2013).

Apart from obtaining and acquiring knowledge among the tasks of the education process its educational role, formative, propedeutic and developing roles have to be mentioned too. As aptly stated by Petlák E. (2004, 67), "according to the recent perception of the education process it is not only about teachers transmitting knowledge to students but also about teachers using the so-called drivers of the education process. By this I mean a conflict between the cognitive and practical tasks on the one hand and the actual level of knowledge, competences, skills and mental attitude of students on the other hand. The essence of this motive power is the contradiction between the two sides of the same 
process (tasks, questions, exercises etc. on the one hand, finding answers, solutions etc., on the other). "The dducation process is therefore a multilateral process with the objective of, as aptly stated by Petlák E. (2004, 65), "gaining new knowledge, competences, skills and habits."

Of course, the degree and intensity of the education process depends on various factors, one of which is the age group of students. As far as the first level of primary education is concerned, the emphasis should be laid on perception, memorising and mechanical learning. However, teachers on the secondary level of primary education should focus on logical learning, developing the students' logical learning. As part of the education process, mental awareness of students needs to be taken into account too.

The education process, as every purposeful human activity is subject to several laws. These are mainly the following ones:

The law of motivation - which is aimed at evoking a positive attitude in students towards learning in order to raise their interest in it. The actual motivation is divided into intrinsic and extrinsic motivation. Intrinsic motivation is an awareness of the need to learn and it comes from the student himself. Extrinsic motivation comes from the teacher and through the use of his interests and other relevant factors it is heading to initiate students to learn.

The law of reciprocal information - claims that students need to be informed about the results of their activities as often as possible in the education process. Horvathová and Szököl (2013, 24) explains that "a systematic informing of students of their performance, accuracy or inaccuracy when solving tasks or exercise, etc." is required.

Transfer Act - means the possibility of students in the education process to use all the knowledge and information at their disposal. 
The law of revision - indicates the need for constant revision of topics which have already been covered and the need to teach students how to apply the knowledge and skills that they have already mastered in practice correctly.

Education processes can be understood in various senses. If it is a process which focuses on teaching a specific topic from a specific area of a particular school subject, we talk about a lesson. The education process can, however, be a termly curriculum too, which students should acquire.

Following the above-mentioned facts, the education process is divided into several phases which may individually vary depending on the length and type of the process.

\section{The education process is made up of the following phases:}

motivation phase or student preparation for mastering a particular topic. During this phase the teacher should stimulate students' interest in the topic that they are going to study;

developmental phase or the phase when students get familiar with a new topic. In this phase, the teacher tries to ensure that students learn what is expected from them,

fixation phase, or primary revision which is aimed at consolidating students' knowledge,

diagnostic phase of students' knowledge, competence, skills and habits. At this stage, the teacher needs to identify the degree up to which the students have mastered the topic. Early recognition of the fact that students are not sufficiently familiar with the topic 
is of great importance in the education process, because if it is necessary, the teacher can explain everything that students feel uncertain about one more time.

application phase or the use of knowledge, competences and skills. Students get a chance to apply the knowledge that they have acquired respectively should have acquired to practice.

In relation to the education process it is necessary to include that part too, in which the teacher focuses on evaluating and grading the students. This is the phase when the teacher has the possibility to identify what the students have managed to master from the topic that was covered and also parts of the topic that students are still uncertain about, that requires further explanation. Thus, an important tool for every teacher can be a detailed analysis of the lesson in which student evaluation and subsequent grading plays a significant role.

So, after checking the number of students present on the lesson and identifying the reason why the missing students are absent, it is appropriate to carry out standard, individual examination from the previous topic right at the beginning of the lesson; it is recommended to keep to this procedure rather than have it unexpectedly. The number of examined students should be indefinite; the teacher should try to provoke a discussion among students. At the beginning of the teaching process (lesson) the teacher also could check by asking some not too complicated, simple questions whether the students know something about the new topic or have some experience with it (for example in case of practice). At the end of the lesson it is recommended to revise; by 
asking questions the teacher finds out whether the students have understood the new topic.

The teaching process may in its simplest, mechanical sense, be perceived as the operation of two basic components: the control component, which is represented mainly by the teacher and teaching resources, and the controlled component, which is represented by the students. In this sense the education process can be more simply understood as a controlled process that consists of two phases. One of them is to provide new knowledge; the other is to control the quantity and quality of the acquired knowledge and skills (Chráska 1998). The two phases constitute a coherent entity. For the optimal functioning of the education process it is therefore essential that the two phases are complementary and mutually interlinked. Affiliation is realized through communication between the teacher and students. It consists of three information channels which carry the curriculum, instructions, guidelines, etc., and also feedback on how much knowledge the students have acquired from the curriculum and information about the teacher's reactions to student performance (evaluation, correcting mistakes and so on).

According to Cangelossi (1994, 22), the education process is carried out through the following six phases: identifying students' needs, setting teaching goals, selecting learning activities, preparing for the teaching activity, supervising and organising the learning activities of students and assessing the degree of achieving teaching goals. As the author later explains elsewhere (Cangelossi 1994, 109), by the sixth step in the education process he means the evaluation of students' progress. Such an evaluation, however, is considered rather short, especially if it is carried out as the last, final phase of the education process. Such an assessment may be useful for evaluating the learning outcomes; however, the importance of 
evaluating the process is not realized in the model. On the contrary, Kolar and Vališová $(2009,49)$ emphasize its importance. They call it the content analysis of performance. Content analysis of performance means that "the teacher alone or together with the student informs him about what he has mastered, learned with how much effort respectively whose help was necessary."

The very purpose of such evaluation is to also evaluate whether the working procedure itself was correct and to inform students about the errors that they made, suggest correction and eventually re-evaluate the procedure and the learning style. At the same time, as the authors correctly point out, this evaluation is significantly heading not only towards the formation of learning strategies and styles, but it also contributes to building the qualities necessary for learning. I believe that ultimately the content analysis of performance carries the potential to contribute to the improvement of the relationship between the teacher and students. The reason for this is that it increases students' trust in the teacher who helps them in the learning process, directs and facilitates their work. By the content analysis of performance the regulatory function of educational evaluation is implemented too (for details see Sections 3.2).

Therefore, I find the definition by Obdržálek $(2003,56)$ more precise, because it claims that the main aspect according to which the education process should be assessed is the relationship between teaching, or more precisely the teacher's activities and learning, by which students' activities are meant. Kolar and Šikulová (2009, 38) also consider the teacher-student relationship as an important phenomenon of education and claim that it greatly determines educational evaluation. Since the teacher-student relationship is discussed in details in a further part of the publication, in this chapter I will not go into details. 
I much rather return to the conditions of the education process, which is the topic of this chapter. For a better orientation in the coming part I provide the reader with the division and structuring of the chapter. In the chapter, the reader will not find independent states of the external and internal conditions of the education process. I have chosen a form of presentation of these factors that enables us to holistic thinking on the education process, and that is finding the relationship between the external and internal conditions and participants of the education process. At the same time I realized that the nature of the education process is historically and socio-politically conditioned, it represents the current value of preference in the society. It is therefore logical that there are a number of educational policies. Thus, defining the concepts of the education and learning process in this publication is not an end in itself. Quite the contrary, I gave them space so that we can discern how the content and operation of the education process varies not only according to the external and internal conditions (Subchapter 2.1 The concepts of the education process) but also according to the personal concept of the teacher (Subchapter 2.2 The teacher's personality in relation to the educational concept).

Finally, defining the concepts of education made it obvious that they also have an influence on how the evaluation in the education process is viewed, which is in terms of the monograph a key moment. However, I will analyse this topic in the next chapter. 


\subsection{THE CONCEPTS OF THE EDUCATION PROCESS}

The character of the education process is among others historically and socio-politically conditioned, it means that it reflects upon the development of society in a particular historical stage, it represents the opinions, beliefs, values of the political elite. The current state of the knowledge of the world as well as the level of science and technology is used in pedagogy and didactics too. Logically, therefore, a number of different types, respectively concepts of the education process have developed, which, as pointed out by Turek $(2008,21)$, still exist in our schools and they blend together. Slavík $(1999,26)$ cites a definition of the education concept by Meighan as "a large and internally linked system of ideas and beliefs on education, which is reflected in the behaviour and communication of that particular group of people who share them."

Several authors have attempted to define the concept of education. Bertrand (1998) has defined seven concepts; spiritualist, personalistic, cognitive psychological, technology, socio-cognitive, social, academic. Petlák $(2004,49)$ present three concepts, more precisely three directions of the philosophy of education: social and personal progressivism, essentialism and reconstructionism. Social progressives regard education a process of preparing a child for adulthood and life in a democratic society. Personal progressives argue that teaching must be "tailor-made" according to the diverse needs and interests of students. They reject the idea of a fixed preset curriculum which, without taking the students' individual circumstances into consideration, stiffly organizes and determines what and how they should learn. According to the philosophy of essentialism, the school gives students 
the knowledge, skills, attitudes necessary to be able to exist as fully developed, mature human beings. If students want to reach maturity, they must understand the outside world, which is based both on observable phenomena and abstract ideas (Petlák., 2004, 68). The philosophy of reconstructionism is characterized by the belief that schools should prepare future adult members of society well enough to be able to initiate social changes and work on their implementation (Petlák., 2004, 69).

Kolar and Šikulová $(2009,23)$, with the support of Meighan's resolution, talk about 3 basic educational concepts: transmissive, interpretative and autonomous. The transmissive concept historically preceded the dogmatic type of teaching that prevailed during the Middle Ages. Its starting point was the conviction that knowledge is made up of firm and well-arranged amount of information that students have learned by heart. Remembering meant knowing. At the beginning of modern times some philosophers and later teachers emerged (including the Czech Comenius), who improved this model. They had no doubts that wisdom is a clear and closed set of knowledge (Comenius called it pansofia), however, they very urgently insisted that students first needed to understand what was to be learned, then internally sort it out and then save it to their memory. Thus, gradually a new image of education was created.

The transmissive concept, or the traditional type of the education process, also called the classical model, or exemplificative model in education was conducted mainly during the 19th century. The teaching method played an important role in this model (Lapitka et al., 2009, 7). It is close to ideas of the so-called academic theories of education of Bertrand or pedagogical essentialism of Pascha et al. In the transmissive concept the responsibility is fully entrusted 
to the teacher, whose task is to transfer the values recognised by society to students.

Almost all teachers of the modern period have sought to discover and suggest the most effective methods and techniques in teaching so that the process of acquiring knowledge was accelerated, deepened and rationalized. Comenius was particularly keen on this and relying on Descartes' method of philosophical cognition he successfully adapted it to the education of children and youth of his time. The didactic approach has the following construction: the teacher has to organize the curriculum in ascending order of novelty, he has to explain the topic, prove the correctness of individual opinions and claims and by visualizing he should show students the essence of the phenomena. Students should listen to the teacher's explanation carefully, note down the new information and as a feedback for the teacher they should practice the acquired knowledge and prove that they understand it. At home students are supposed to learn some texts by heart, and then the teacher checks in various ways if students have mastered the prescribed text (Lapitka et al. 2009 7). In contrast to dogmatic teaching the teacher is trying to explain, illustrate, justify the curriculum, he uses visual teaching aids because this way it is easier to understand and remember any kind of information. This process is aptly demonstrated by the classically known Herbart triangle (children, curriculum, teacher). True, this model also rests on the unaltered perception of the basic educational interaction, where the teacher is the carrier of knowledge, and the student is the object that has to master the knowledge. The biggest flaw of this type of education process is the shallow reproduction of foreign ideas, says Turek $(2008,23)$. This type of education process is based on behavioural theories of learning that notice and present 
observable behaviours through relations maintained by initiatives and responses, while they try to explain that the behaviour of individuals is influenced by environmental factors (Kostrub 2008, 16). In school practice, this means that a student who successfully solves the task is praised, which in turn leads him to actively acquire new knowledge, (Kostrub 2008, 16), for which the teacher once again rewards him. Behavioural theories, warns Kostrub (2008, 17) tend to underestimate the effects of biological and unconscious factors in human behaviour as well as the importance of intrinsic motivation and self-determination.

At the turn of the 19th and 20th centuries the experimental psychology spread and its pioneering contribution was that it decided to examine the actual behaviour of learners first on animals (Pavlov on dogs, Thorndike on mice, the German Gestaltists on monkeys, later Skinner on pigeons etc.). Based on analogies, different theories and concepts appeared of education in particular by American teachers (J. Dewey, H. Parkhurst, C. Washburne, but before them in Europe too, for example Montessori), who tried to rethink the traditional organization of teaching and classical educational interaction in which the teacher teaches and the students acquire knowledge and information and pass the initiative of gaining knowledge to students (the so called active school - Lapitka et al., 2009, 9). This gave rise to the concept of interpretive education (similar to Bertrand's personal, child-oriented educational theories or the essentialism of Pasch), which claims that knowledge gained from students' personal experience should get into the focus of their conscious attention and its subsequent interpretation should be improved and complemented with the already existing knowledge. The teacher is in the interpretive concept regarded as the initiator 
of the dialogue in which students, based on the comparison and interpretation of their own experience, with the help of the teacher obtain further knowledge. The role of the teacher is to encourage confrontation of students' experience, provide them with support when it comes to interpreting. The students' task is to reveal the differences and similarities between various experiences in the class. On this basis, students discover new knowledge.

The alternative methods of education pushed the perception of didactics and pedagogy towards a third, so called modern type of education process, which Lapitka et al. $(2009,9)$ also called a constructivist type or Meighan (in Kolar, Šikulová 2009 23) an autonomous concept. It gives prominence to self-education, self-reflection and the students' right to choose their own path to knowledge. It is related to the social theory of education (Bertrand 1998) or reconstructionism (Pasch et al., 1998). It is based on the belief that schools have to prepare future adult citizens to be able to make independent decisions and foster social changes. Its main element is that students' knowledge and skills should be the result of their own thinking, their active work, supervised by the teacher. This means that knowledge is constructed and transformed by the individual on the basis of the mental processes carried out within his mind. Knowledge is not immutable; it is dynamically changing depending on its initial level as well as the external and internal activities that are aimed at its development (Kostrub 2008, 41). Autonomous access develops a higher level of thinking that allows one to reflect on his own behaviour, i.e. to think about what he has done and take responsibility for it. The teacher is the organizer of the student's experience with learning, he helps the student to understand and control his own cognitive processes. The role of the teacher is to bring students to 
independent judgement and decision. Although at the beginning, the responsibility is fully vested in the teacher, gradually students learn to assume responsibility to such extent that they internalize it. As a consequence they approach the process of self-evaluation seriously. The student's task is to master the art of acquiring knowledge, asking the question: How can I discover this or that? Evaluation should provide students with feedback and knowledge about the education process.

Cognitive constructivism is another significant method, for which the experimental and theoretical work of the Swiss psychologist Piaget became a springboard (Lapitka in 2009, 9). Jean Piaget devoted his life to the ontogenesis of human thinking focusing mainly on childhood and younger school age. Emphasizing the cognitive operations was undoubtedly the most valuable asset of Piaget's school. Piaget studied how these operations emerge and grow what role they play in the process of spontaneous learning in childhood. Pedagogy accepted its division between specific cognitive operations (cognitive operations when manipulating with things) and abstract cognitive operations focusing on the connection between abstract phenomena and categories. The educational legacy of these discoveries were further developed by Jerome Bruner (Lapitka in 2009, 9) who pointed out the importance of key terms and concepts in education and concluded that the construction of the learning content must begin with the key terms. The educational content standards is a distant result of his initiative. Cognitive operations were further developed in education by Benjamin Bloom who set a hierarchy of cognitive processes, compiled them into a pyramid, from the simplest to the most demanding. This construction found its way into practice as Bloom's taxonomy of cognitive operations or educational goals. 
The application of cognitive constructivism in the education process starts from the assumption that before mastering a new topic the teacher identifies the expectations, experience and also the knowledge that students have about it, namely their preconceptions. The role of the teacher in terms of the cognitive constructivists is to provide students with such experience that results in a cognitive conflict with their preconceptions. In order to find new solutions, students need to be active because this is how they will manage to overcome the conflict. This is also the basis of problem-oriented education (Turek, 2008, 394). The method of social constructivism focuses on the cultural and social conditions of education as well as on social interaction within the learning mechanisms. It assumes that a person constructs his knowledge by interacting with the environment, which also includes other people. This interaction triggers change both in the individual and in his environment (Turek, 2008, 395).

The concept of constructivism is based on the tendency that sees the teacher's role in supervising student learning activity, in providing the help necessary for the development of the basics of critical thinking and learning as well as for obtaining the skill to search for new information on their own initiative. The education process began to be seen as monitoring student learning activities. The theory of constructivism and practice not only confront students respectively groups of students with the problems to be addressed, but these problematic tasks are designed to fit the content of a scientific discipline transformed into a school subject with regard to the specific development of students' cognitive operations. The change of didactic principles called for a change in the organization of education and adjustment of the teaching aids, especially textbooks. In this arrangement the classical lesson following the 
pattern of introduction - testing - explanation - practicing was cast aside only to be used in specific cases. The beginning of the lesson generally has a stimulating character, with a brief explanation of the particular problem. Traditional testing absurdly taking place at the beginning of the lesson and condemning the untested part of the class to demonstrate boredom and indifference, practically disappeared, or even if it persisted, its character has changed. The expectations from teachers are constantly increasing because they are supposed to be the organizers, initiators, facilitators, diagnostics, prognostics, advisors for students and parents, they are expected to have suitable pedagogical, psychological and didactic competencies and to create optimal conditions for the individual development and progress of each individual. The modern type of education process in the literature of didactics has different conceptual definitions such as humanistic oriented learning process ( $\breve{S v e c} 2005,46$ ). However, this is an extremely complex operation, requiring a thorough preparation. If a teacher wants to be successful, he has to get to know each of his students and based on the individual peculiarities, he has to plan, organize and prepare each activity in a way that the content of education is accessible and understandable for everyone, with different assumptions. In order to make the education process optimal and efficient, the teacher must implement a differentiated teaching process and in terms of a modern approach rely on differential didactics (Szőköl, 2010, 165). Differential didactics is based on a profound knowledge of general and pedagogical diagnostics, because in addition to the theoretical level it largely comprises the application level. Its aim is to find and analyze the peculiarities in the education process, because there is a large number of differentiations and their consequences in education. 


\subsection{THE TEACHER'S PERSONALITY IN RELATION TO THE EDUCATIONAL CONCEPT}

The teacher is a crucial factor in the education process. He is a professional, who is well prepared to perceive and shape the students' personality and develop their skills by educational activities (Dytrtová-Krhutová 2009, 16). If the teacher is to meet these challenges effectively, he has to be an expert in his specialization, have very good educational training and needs to be well-informed culture-wise (Turek 2008, 122). Kostrub (2008, 107) argues that a good teacher doesn't even start teaching unless he knows the curriculum very well, understands it and has a wellconsidered teaching approach with methodology and recognizes the educational objectives that students and their learning processes should focus on. All this results in what I point out in accordance with Manniová $(2008,69)$ that the teacher's personality is reflected in three essential areas. The epistemological profiling of the teacher's personality creates a wide, deeply educational and professional basis. The axiological profiling of the teacher's personality is generated by a broad understanding of the teacher's value orientation (developed personality traits and abilities to explore, improve himself in accordance with the emotional, intellectual and moral aspects of the teacher's personality and acting within moral, ethical values). The praxeological profiling of the teacher's personality establishes practical skills with behaviour, deeds and skills, "not only in the school but also outside it, because the teacher should be an example for their students, a model" (Turek 2008, 122).

Each teacher individually modifies and specifies the universally formulated requirements, principles, content of education, as a 
unique, specific human being that has his model of personality (Manniová, 2008, 83). These factors contribute to teachers' typology. Typology, as emphasized by Dytrtová and Krhutová $(2009,18)$, is not intended for labelling teachers, it is much more heading to describing the professional aspects of teacher's personality in order to influence it. Typology is just one of the attempts searching for the optimal profile of the teacher's personality. In this monograph I have no ambitions to make further efforts in this direction. My aim is to provide the reader only with a brief presentation of the best known personality types of teachers, the characteristics of which will move us to defining the teacher's teaching style and consequently to the teacher's comprehension of teaching.

One of the best known typology is Caselmann's typology (according to Turek 2008, 137) that he created on the basis of the teacher's relation to students and orientation to learning, the school subject and the students' personality, according to radicalism that is determined by the everyday behaviour of the teacher in the classroom and also according to the relation of the signal system (Manniová 2008, 84). There are two types of teachers distinguished: one of them is the logotrop type that focuses primarily on the curriculum, in fact, this kind of a teacher notes the curriculum more than the students. The other one is the paidotrop type that focuses mainly on the students, this type of a teacher is more interested in the students than in the curriculum, he respects their age and the individual characteristics. Lewin's typology (by Dytrtová-Krhutová 2009, 19), which is formulated on the basis of experiments aimed at exploring different styles of education, distinguishes three types of teachers. The autocratic, the democratic and the liberal type, while the criteria for this division 
includes the climate in the classroom, organizing teaching and the teacher's relation to students (for more Turek 2008, 137).

Due to changes in the perception of teachers nowadays, their role in the didactic process, the classical typology of teachers' personality is now obsolete. There are new typologies created which take into account the new criteria of division and reflect on the socio-political context of education. I personally consider interesting that kind of typology which reflects on the teacher's attitude to reform changes. According to this criterion, teachers are divided into traditionalists (they have a fundamentally negative attitude to reforms, they refuse to incorporate any reform elements in their work) and chameleons (who have an ambivalent attitude to reforms). This typology, however, as reported by Dytrtová and Krhutová $(2009,19)$ is not empirically verified. Attitude to reforms and the change of the teachers' status also appear at Kostrub (2008, 116), who claims that the teacher as an innovator, researcher, designer, and so on, is another requirement of the present. So is the reform to change the role of today's teachers who are influenced by more recent views on the didactic organization of the education process.

The typology of teachers' personality is therefore currently in most cases based on the teacher's work, his preferences of certain procedures and approaches to students and, thus, typology has been enriched by the typology based on their teaching and interactive style. Teaching style can be understood as a specific individual way of teaching, which is preferred in certain periods and in certain contexts. It is manifested by specific strategies and methods of supervising the learning activities of students, by the choice of a particular organizational form of teaching as well as the teaching methods and processes, the preference of certain 
types of material and teaching resources and by the choice of basic communication patterns during teaching (Skoda-Doulík 2011, 68).

The basis for the teacher to take the reality into consideration and to plan teaching, for his actions on the lesson, for his perception of teaching as well as the evaluation of educational reality and himself is the so called teacher's concept of education (Hupková-Petlák 2004, 37). Please note that in this area, educational terminology is considerably fragmented, it is full of different expressions, such as the teacher's individual approach to education (Hlásna, 2008), the teacher's educational thinking (Průcha 1997, 190), the methodology of teaching (Kostrub 2008, 116).

The teacher's individual conception of education is the result of the evolutionary development established by the teacher's educational concept. The teacher's educational concept is a set of his personal views, beliefs and attitudes, arguments that the teacher uses to justify his concept. It is implicit, subjective, relatively stereotypical and stable. Establishing the idea of teaching takes place in three stages (Hupková-Petlák 2004, 40). Preconceptions of the idea of teaching - constructed on the basis of intuitive beliefs, attitudes shaped by their own childhood experience and subjective experience in the role of a student. Early individual teaching concept - intuitive, relatively unconscious teaching concept that takes the form of a practical theory (weakening of the preconceptions based on the education at the faculty of education and educational activities in the practice in harmony with the school reality and the first experience in teacher's position). Forming a rational (the theoretically reflected) concept of teaching - it is formed through a systematic self-reflection and theoretical reflection of practical experience and is heading to awareness, brightening, better comprehension and understanding the broader 
context of educational events. The teacher is able to retrospectively reflect on his work to examine it critically, to realize the conditions of his actions and decision-making processes. He can design the work, reflect on it, correct it and put it in practice .

One of the important elements of the teacher's individual concept of education is how he perceives the particular student. It is based on the judgement that he made about the student (Kolářr-Šikulová 2009 39) which basically determines the overall nature of the relationship between them. The teacher's perception of students is formed gradually, starting with a systematic, intentional observation followed by their psychological and social development, monitoring their attitude to school and to learning, self-motivation and later by recognizing their preferred learning style. Consequently the teacher will be able to adjust his teaching style to the peculiarities that he has identified. The image that the teacher creates of the students is the result of interaction of many factors, objective and subjective factors, which need to be taken into consideration very carefully. These factors appear both on the teacher's and students' side. Kolar and Šikulová $(2009,40)$ report three factors identified by Pelikán that affect the teacher's perception and conception of the students. These are confrontational factors that arise on the basis of the comparison as a result of his own experience or the teacher's expectations. Factors associated with the general regularities of human perception lie in the selectivity of information, which means that the teacher from the amount of information that he has collected, chooses only that which is in accordance with his opinion, confirms his view. The rest remains unnoticed. Irrational factors are based on likes and dislikes which are very hard to explain and grasp, yet in the teacher-student relationship they significantly present and influence the image that 
the teacher has of the student. In addition, this image is influenced by factors from the student's side. These include, but are not limited to the following factors which I have listed in accordance with Cangelossi (1994, 26); the interest in learning, self-confidence, the perception of what is important, attitude towards school, cognitive abilities, previous results, experience, family and social life, specific, individual needs of the student. The overall image of the student, which is influenced by many of these factors, is significantly reflected in the evaluation which I will address in the next chapter.

Based on the most commonly applied theories of teaching in the educational process, the teacher's individual educational concept and the perception of the curriculum goals, strategies, methods applied in teaching and other components of the teacher's idea of teaching which are associated with the educational concept may have a behavioural, humanistic or socio-cognitive orientation. In the coming part, in accordance with Švec $(2005,101)$, I briefly clarify the nature of each individual educational concept.

\subsubsection{Behaviorally oriented individual educational concept}

The behavioural concept is characterised by the predominance of transmissive transfer of completed knowledge and information. The teacher chooses the curriculum by linear sequence. Teaching is characterised by a summary structured content in terms of finite - completed verbalized knowledge (Kostrub 2008, 117). As far as communication is concerned the one-way, so the teacher communicating to students is dominant. The behavioural approach in teaching prefers the controlled interventions and instructions 
which come from the teacher and head towards students. The teacher expresses his requirements, gives instructions, directs, and gives orders pertaining to the nature of the curriculum through classroom tasks that students have to fulfil. The tasks, their fulfilment and the performance are evaluated by the teacher who also gives further instructions, regulations, and assignments. He provides the students with information that is taken from somewhere or it is his own, concepts, models, examples, etc., without the possibility of asking questions and thinking by the learner. He feels no need to adjust the curriculum to the students; the level of their experience is not identified. He asks students simple and very straightforward questions that require mechanical reproduction of the curriculum. The most important requirement for the students is a good memory. If they are calm, attentive, trying to understand and know, they are usually successful. The evaluation given by the teacher shall stand.

Students in the thus interpreted education process are not allowed to carry out learning requiring greater involvement of reasoning and more demanding cognitive operations. Therefore, they dwell mostly on the level of applying the reproduced knowledge and from the mental processes they apply mainly attention and memory. The primary operation and sufficient student performance is processing the curriculum and subsequently reproducing it.

\subsubsection{Human-oriented individual educational concept}

Humanistic psychology is an approach that was created as a response to psychoanalysis and behaviourism. While psychoanalysis focused on the unconscious, behaviourism 
focused on human behaviour. In the humanistic conception of education the teacher - facilitator is anybody that accompanies and encourages students on their journey of learning and personal development, growth. The facilitating teacher shares the responsibility for the learning process with students, he provides resources for learning (personal experience, books, social sources), focuses on promoting a continuous process of learning (how to learn) leads students to achieving their personal goals by self-discipline (the transition from extrinsic to intrinsic motivation) and leads students to evaluate their knowledge on their own. The facilitating teacher thus gives up the "power" over the others and consequently controls only himself. The power of making decisions is in the hands of an individual or individuals who it concerns. Therefore, the learner remains in the centre of attention. When talking about the humanistic nature of education, we have to point out that it is characterized by deep relationships between the teacher and the students as well as among students.

The traditions and knowledge of humanistic psychology in education are represented mainly in alternative schools. Humanoriented individual concepts of education emphasize:

- Developing the student as a unique person,

- Fully accepting the student,

- Promoting the student's internal tendencies towards selfrealization,

- Relying on personal experience,

- By provoking, experiencing higher values such as beauty, goodness, love, harmony, and so on, expanding the limits. 
The individual educational concept applying the principle of humanism, is based on a true individual development of students according to their possibilities and abilities, where the aim is that everyone remains an individual human being, everybody stays himself. School in terms of humanism is understood as a living community, the forms and methods of education are selected by mutual agreement between the teacher, students and parents. The educational environment is extended beyond the classroom and the school because it is based on the principle that learning is based on life and everybody learns for life. A particular emphasis is placed on empathy and communication. The student's personality is in the centre of teaching and the educational activities are carried out in accordance with his individuality.

\subsubsection{Socio-cognitive, cognitive-oriented individual educational method}

The current school policy prefers the socio-cognitive educational theory, which emphasizes the development of cognitive skills freely applicable to a wide range of intellectual problems and tasks. Zelina $(2000,70)$ is also of the same opinion; "The purpose of education is to work towards a gradual development of cognitive functions and processes, based on their complex development in order to achieve the cognitive goals resulting from these taxonomies, structures". This structure organizes thinking, starting with lower processes and moves towards higher cognitive processes and functions.

In the constructivist concept of education the student acts as a discoverer of the world and in his mind the idea of reality is 
formed. The basis of learning in a constructivist understanding is searching for a solution to the cognitive conflict, the transition from ideas, isolated facts to constructing knowledge. Knowledge is thus constructed individually in students' minds. The new information is processed according to the knowledge that students have. It changes the modes of thinking, reconstructs the older cognitive structures and creates new ones.

The basic ideas of constructivism appeared in the so called personal constructivism version, later they found the way to social constructivism. The representative of constructivism is J. Piaget, whereas social constructivism is represented by L. S. Vygotsky who is nowadays more accepted. Piaget emphasizes that there is no difference between the functional aspect of how a child and adult learn, they both need an incentive to do what they are required to. The only difference is in the structure of their thinking (Alexovičová 2007, 27). He concentrated on obtaining knowledge from the physical reality. The aim of such teaching is to enable students to present the experience they have already learned. The teacher takes the role of a facilitator; he initiates a cognitive conflict between the students' preconceptions and the new experience that they have obtained during the learning process. Addressing the cognitive conflict requires an active, hardworking student, who proposes ideas, solves problems, asks questions and searches for answers, differences and similarities.

Vygotsky emphasizes that when shaping the individual conscience the direct contact of the child with the physical reality is enhanced by a direct contact with cultural instruments which already represent the primary physical contact. The relationship between man and the physical reality is therefore mediated, because one grabs the world in already accomplished cognitive 
categories which are provided to him by his culture. What must be processed intellectually is not the complexity of his cognitive relation to reality, but the importance of the mechanism by which the primary physical relation to reality is mediated to him. For this reason it is said that thinking (together with knowledge) is socially mediated and that is why it is called social constructivism. Socioconstructivism emphasizes the social and cultural interactions and transactions that are of utmost importance in shaping knowledge. The source of students' learning in the education process is a socio-cognitive conflict, i.e. conflict between the thinking of the individual and the thinking of the others which results in a change of thinking and acting of those involved. The individual learning concept, which applies the principles of socio-cognitive learning theory, is characterized by two processes: co-operation as an organized participation and collaboration in solving educational problems (Kostrub 2008, 117). Students select the tasks together with the teacher, formulate subtasks and work processes, address these challenges together in groups and discuss them. They reflect their own work as well as that of the whole group, the product of their work and the findings of the task solution. The teacher creates a friendly, accepting and conducive environment to ensure that students have the opportunity to confront and discuss their knowledge, experience and expertise with the others by relying on the cyclically repetitive reflection. He gives students space to discuss their observations, reflect on them and justify their opinions, attitudes, knowledge. Thus the teacher offers students the opportunity to confront their previous experience with the new socio-cultural context. This is the way how a student becomes an active member of a learning group. 
These three concepts in practice, as Slavík points out (1999), are reflected in educational programs most specifically in teachers' behaviour and in the evaluation methods they use, which I will focus on in the following chapter of the monograph.

\section{SUMMARY}

The second chapter of the monograph, The qualitative transformation of understanding the essence of education process and learning is divided into two subsections: The concepts of the education process and The teacher's personality in relation to the educational concept. At the beginning of the second chapter, I briefly defined the essence of the educational concept. I pointed out that the education process is an intentionally controlled, systematic and organized process between teachers and students in the social environment of the school, in which a sequence of cognitive, learning-oriented operations and non-cognitive actions aimed at the social and personal education in real or simulated situations take place. It is also affected by the conditions in which it happens. External conditions represent the nature of socio-historical, cultural, political and social context which have an impact on how the education process is understood. I pointed this out in subchapter 2.1 The concepts of the education process. I have included three basic educational concepts: the transmissive, which was historically preceded by the dogmatic type of teaching, the interpretative and the autonomous. I have defined their historical and social backgrounds. The starting point of the dogmatic type of teaching was the belief that knowledge is a clearly arranged amount of knowledge that students learn 
mainly by memorizing. This idea was later modified by realizing that in order to memorize some information first it needs to be understood. This effort was manifested in the transmissive teaching concept, which sought to discover or propose an effective method and technique in teaching, in order to speed up the process of acquiring knowledge. I pointed out that this type of education is based on behavioural theories of learning that notice and present externally observable behaviours through relations maintained by signals and responses. Efforts to reassess the traditional organization of teaching and classical educational interactions resulted in the interpretive concept of education, which emphasizes the importance of putting knowledge from the students' personal experience in the focus of their conscious attention. This should be followed by interpretations associated with improving, specifying and complementing knowledge. I emphasized that the concept of teachers' and students' status in these concepts changes. Alternative methods of education moved the understanding of didactics towards the autonomous concept, which gives prominence to students' self-education, selfreflection and their right to choose their own path to knowledge. I emphasized cognitive constructivism and social constructivism. The former presupposes that the teacher before making students master the new topic identifies their preconceptions and the latter assumes that students construct their knowledge by interacting with the environment. This can, of course, be seen in the increased expectations from the teachers who are expected to be organizers, initiators, facilitators, diagnosticians. They are also supposed to have the necessary competencies to create optimal conditions for the individual development of each student. 
In subchapter 2.2 'The teacher's personality in relation to the concept of teaching', I found that the teacher's personality is reflected in three essential areas: epistemological (deep educational and professional basis), axiological (the teacher's value orientation) and praxeological (practical skills). I also mentioned teachers' typology that allows description and schematisation of the professional aspects of teacher's personality in order to influence it. I presented the best known typology of teachers' personality. I noted that the current teachers' personality typology is most often based on the style of their work and their teaching style preferences. I also pointed out that the starting point for planning teaching is the teacher's concept, the so called individual concept of education which is the result of the teachers' evolutionary development of creating the idea of education (preconceptions of teaching, early individual concept of teaching, shaping the rational concepts of teaching). As one of the important elements of the teachers' individual teaching concepts I mentioned their perception of students, which plays an important role when it comes to students' evaluation. I briefly explained different individual teaching concepts: behavioural, humanistic, socio-cognitive oriented individual concepts of teaching. I have pointed out that these three concepts are in practice the most noticeable in the teachers' behaviour and the evaluation method they use. 


\section{THE CONCEPTS, FUNCTIONS AND DIMENSIONS OF EDUCATIONAL EVALUATION}

This chapter demonstrates how the view on evaluation in the education process changes depending on the concepts of teaching. Five current concepts of educational evaluation are identified: the concept of competition in educational evaluation, the concept of non-competition in educational evaluation, the cooperative concept of educational evaluation and relying on domestic literature the humanistic approach and the concept of development in educational evaluation are also introduced. Further, I characterize the different functions of educational evaluation which have gradually emerged as demands grew for evaluation. I offer an inspiring classification of the evaluation function according to the purpose they fulfil in the educational process: developing-formative function, the function of feedback, informative function, the function of greater efficiency and the differentiating function. By defining the functions of educational evaluation I aim to determine its dimensions, which I consider to be important in order to get a more plastic picture of the process as well as the means and methods applicable in educational evaluation. From this aspect, I further differentiate the personality and social dimensions, the didactic dimension and the social dimension of educational evaluation.

Evaluation in one's life fulfils different functions depending mostly on the purpose, object and subject of evaluation, the environment and the conditions of evaluation. Evaluation conducted at the school is a prerequisite for successful and effective teacher's work. Teachers who realize the potential of its function for the 
development of students' personality also understand the essence of these functions, and they respect and effectively employ them. Evaluation can encourage students positively towards further work, or, quite the contrary, it can also dissuade them from it. What the effectiveness of the teacher's evaluating actions will be depends largely on how deeply the teacher knows the students, and how their individual values and priorities are respected.

\subsection{THE CONCEPTS OF EVALUATION IN RELATION TO THE CONCEPTS OF EDUCATION}

What is actually evaluated in education in terms of student performance or their learning activities depends not only on the teacher's personal conception of the teaching itself, but also on some general concepts of education. The concept of evaluation gives a comprehensive view on the issue from the aspects of defining the process and applying the methods, means and results of evaluation. The prevailing method of looking at educational evaluation is influenced by the individual whom we consider responsible for the achieved learning results. According to Buda (2013), three streams of concepts in educational evaluation can be defined: the concept of competition in educational evaluation, the concept of non-competition and the co-operative concept of educational evaluation.

\subsubsection{The concept of competition in educational evaluation}

This view comprises the semantic essence of competitiveness and rivalry as an important and natural element of human life. In 
society, the individual strives for better job opportunities, career or salary advancement. The school as an educational institution prepares the individual for such society. The role of schools is to provide quality education. Education is viewed as an investment in the future and it is believed that caring for study results is entirely the student's business. Students are therefore considered to be solely responsible for their academic performance. The constant rivalry at schools is a preparation for what the student can expect to happen in life. This concept is based on the assumption that students can and mainly that they want to learn. Each student is considered to be intrinsically motivated, so motivation specifically is not attended to. It is assumed that to achieve good evaluation is the primary goal of each student and the sole fact that they are evaluated is motivating enough and it is not necessary to apply other instruments of motivation. The concept takes it for granted that individuals at schools make all the effort to achieve good scores, just like contestants do in competitions. Differences in performance are therefore considered to exist due to differences in students' abilities.

The concept of competition in terms of educational evaluation emphasizes results and the ranking of students based on their performance. The school must prepare students for the competition by creating optimal conditions and a fair environment. This can only be achieved if the teacher treats all students equally and adjusts the instruments of teaching accordingly. Therefore, the most effective teaching methods appear to be those where the teacher is dominant as the sole bearer of knowledge, transmitting information in a finished form to the students who are acquiring it. It can then be assumed that applying the concept of competition in educational evaluation is allowed primarily by the concept of the traditional 
type of educational process, based on the behavioural theories of learning.

What is the point of competition in school conditions? It is particularly monitoring the process from a lower to a higher level of education. Competition therefore means preparing students to progress to the next stage of school and ultimately enrolling them for further studies.

How does the concept of competition appear in the techniques and methods of evaluation? The emphasis is on ensuring accuracy and objectivity. This is achieved firstly by establishing equal and strictly monitored conditions for all, secondly by the existence of such rules and evaluation criteria which ensure objectivity. This objectivity can be assured by objective evaluation tools, mainly by didactic tests. Their emphasis can easily be moved towards measurable performance, which in practice is often the case. Its consequence is that those areas of performance and skills that are difficult to measure are initially underestimated in evaluations, and later in the classroom as well.

The concept of competition in educational evaluation is present whenever we want to create some sort of achievement rank of individuals. It may be believed that the preparation of students for higher-level schools follows an objective, external evaluation criteria expressed in the expectations and claims of the school related to the applicant. In reality, however, these expectations are relative and conditional upon the performance of the students studying at the given school, so they are not the school's real expectations.

What are the problem areas of applying the concept of competition in educational evaluation?

1. It is not possible to consider the argument about students wanting and being able to learn as generally applicable. The expansion 
of education, the increase in the length of compulsory education and various demographic factors significantly reduce children's intrinsic motivation to achieve good academic results. Schools applying the concept of competition in educational evaluation are not able to support and positively affect such students.

2. Based on the above, it can be concluded that schools are attended by heterogeneous student, either in terms of skills, social composition or background. Whereas differences in the ability of students assume and cause differences in their performance as well, competition loses its meaning. And this is because the achievement rank of students gets created very fast and remains unchangeable.

3. Overexposing the nature of rivalry and the comparison of students to each other can easily lead to labelling and pigeonholing, which does not affect positively the psyche of the student.

4. Rivalry alone cannot be regarded as a generally motivating factor for each student. It is not correct to assume that each student likes competing and winning. The atmosphere of competition can have an utterly negative effect on students who are of introvert, timid and shy nature. The atmosphere of competition for them is the source of constant stress and affects their performance negatively.

5. The concept of competition in educational evaluation does not allow applying the holistic view (as a whole) of individual performances.

6. It is a mistake to believe that solely the students are responsible for their study results. This view distracts attention from the formative influence of the teacher's personality on student development. Teachers are thus placed into the arbitrator's position while the essence of their educational activity escapes them. 
Based on the above, basic assumptions can be formulated related to the functions of the concept of competition in educational evaluation. This concept can be applied in such a study group which:

- is homogeneous in terms of its members' motivation and performance,

- likes competition - thus competition is a stimulating factor for its members, it does not hold them back, but helps them to perform well.

This concept of evaluation is historically the oldest and widely used even today in our schools. During their undergraduate training and also in subsequent teaching activities, many teachers have encountered and applied solely or mainly items of the concept of competition in educational evaluation. Only recent research findings have prompted educators to rethink the concept of competition and enrich it with new elements.

\subsubsection{The concept of non-competition in educational evaluation}

The concept of non-competition in educational evaluation was born in alternative pedagogy as a counterweight to the concept of competition, the basis of which is to deny the importance of competitiveness in school education and evaluation. The focus of alternative pedagogy and thus that of the interpretive concepts of education is the child. Consequently, the role of schools is not to create ideal conditions for the objective rivalry of students 
among themselves in order to succeed in life, but the personal development of each student.

The concept of non-competition in educational evaluation disputes competition and the comparison of students to each other. The main objective of this concept is to encourage and motivate students by rewarding their efforts. Therefore the performance of the individual is in focus, individually guided and commented while carefully avoiding the comparison of students themselves.

Child-centred philosophies say that every child is different and everyone excels at something. Differences in the performance of children are seen in their different motivation and interests. Concentrating on the overall personality and its development expands the range of evaluation and enhances its holistic (complete) character.

The concept of non-competition in educational evaluation considers the teacher responsible for the students' motivation and their learning results.

The problem areas of applying the concept of non-competition in educational evaluation are formulated in the following questions: 1. Is it correct to completely reject the principle of a healthy competition among children? That is, if the focus and the internal value system of the school strongly deviate from the real social environment, the responsible fulfilment of the school's function can be questioned. Namely, if the school lacks constructive criticism and the experience of failure, children will not learn how to react and how to deal with it in real life.

2. Is it right that the teacher is seen as the only responsible factor for the student's success? The teacher's effort to create an interesting and motivating learning environment is only effective if the student is the teacher's partner in those efforts. In the process 
of teaching and learning, there are also moments which are not equally motivating, engaging and stimulating for everyone. The teacher's effort to motivate students and hold their attention at any cost may produce the opposite effect. students quickly get rid of the feeling of responsibility for their study results and the teacher will be the one to blame for their failure.

\subsubsection{The cooperative concept of educational evaluation}

The cooperative concept of educational evaluation sees the essence of educational assessment in providing assistance in learning. Student and teacher are considered equally accountable for the effectiveness of the learning process. What are the practical implications of this conception? If the result is a common product, it is not possible to strictly (fully) separate the role of the subject and object of the evaluation process. It is not only the student who is evaluated, but it also applies to the teaching activity of the teacher (preparedness, methodical skills, employing the teacherstudent relationship, etc.). The cooperative concept of evaluation thrives particularly in the conditions of the autonomous concept of education, which gives priority, as we mentioned above, to selfeducation, self-reflection and the rightfulness of the student's own path to knowledge.

It is therefore necessary to involve students in the evaluation process as much as possible, especially when:

- setting the objectives of evaluation, including evaluation criteria,

- drawing up rules and the evaluation system,

- conducting the assessment itself. 
The advantages of the cooperative concept of evaluation are obvious. The jointly developed and implemented evaluation motivates students and teachers equally, which increases the effectiveness of learning and teaching. However, it is not a panacea and cannot be applied always and everywhere. In order for the cooperative approach to be effective, several conditions must be fulfilled. An absolute priority is that students are willing and able to take responsibility for common work. This is only possible provided that:

- the teacher and students represent the same interests - it is in everyone's interest to ensure that students acquire maximum knowledge,

- students are able and competent to assess what to expect from the school and the teacher, and how their expectations are fulfilled by the school or the teacher.

If any of the conditions are missing, the cooperative concept of educational evaluation can be applied to a limited extent. It works perfectly in adult education though as adults have a real and quite accurate expectations of the school, the educational activities, the course or the teacher. And meeting their needs should result in the improvement of the quality of education.

Each concept of evaluation has its positive but also negative aspects, and as we presented it earlier, each works well in different conditions. In practice, they are rarely found in pure form, as the various elements of individual concepts usually overlap. What determines which element of the concept dominates the teacher's approach?

1. First of all, it is the philosophy of the school which is created by the school itself based on its potentials, assumptions and recognized values. How the school formulates its own aims and 
the profile of its graduates are mostly reflected in the system and the philosophy of evaluation as well.

2. Secondly, we can mention the age of students involved in the process of education and evaluation. Their age determines if the individual evaluation concept elements are possible to apply. The younger age of students assumes rather the application of the concept of non-competition than the concept of competition in evaluation. At this age, however, the cooperative concept of evaluation is inappropriate because students cannot yet assess the meaning and purpose of teaching, the objectives and priorities of evaluation, nor the effectiveness of education.

3. Each group of students is distinctive. Educational evaluation in the process of education is not an end in itself and therefore without the students' direct participation it cannot be decided which of the philosophy of evaluation is the most effective for them. It is necessary to know the students, the specifics of the group, the level of their motivation to study, study aspirations and long-term objectives.

4. Last but not least it is the teacher's personality (see previous section), his or her individual style of work, teaching, as well as one's own educational views and values. These characteristics are determining when deciding which elements of the evaluation concepts feel the closest to one's personality. The teacher should recognize this fact and try to expand the horizons of his or her knowledge, and adapt the culture and the philosophy of evaluation to the current group of students, their needs, expectations and interests in order to achieve efficiency in the teaching and learning process. 
The following two concepts of educational evaluation are presented with the support of domestic professional literature.

\subsubsection{The humanistic-oriented concept of educational evaluation}

As the fundamental basis of humanistic-oriented concept of evaluation, Kosová $(1998,48)$ emphasizes mainly the recognition of the progress in the child's development. What is taken into account is mainly the change in attitude, knowledge and skills in comparison with previous observations from the students'evaluation. Personalityfocused evaluation is not based on fixed scales and ranges that student performance must be crammed into, but its criterion is the evaluation of the students themselves through accurate and specific expressions. Here, knowing the students is very important and this is when we can assess their progress, reserves and possibilities. The author focuses on defining the principles of evaluation and identifies them in the following concepts:

The individual approach in evaluation means not to compare students to each other, but assess their performance according to their individual possibilities, abilities, skills and predispositions. The progress in their performance is assessed. The principle of individual approach allows respecting the students' efforts to achieve goals and deliver a particular performance.

The openness of evaluation is understood in the sense of allowing an individual approach. It is implemented in the daily activities of students through formative evaluation and after a certain time by summative evaluation as well. The openness and formativeness of evaluation confirm that the final product is 
evaluated, which is the work itself, and the student is not judged or condemned.

The positive orientation of evaluation lies in highlighting the positive aspects of the student's activities using a positive formulation, which motivates towards progress and a positive shift.

The complexity of evaluation takes into account not only the knowledge but the attitudes and motives of students as well.

The tendency towards self-assessment and the active involvement of the student in evaluation is understood in terms of the opportunity to participate in creating the evaluation criteria and allowing self-reflection on one's own performance as well as reflection on the performance of fellow students according to preagreed criteria.

Objectification of evaluation is based on limiting the subjective influences of the teacher in evaluation and requires a thorough knowledge of the student.

\subsubsection{The development concept of educational evaluation}

Development evaluation in the learning process is realised in the form of two types of interlinked evaluations, such as:

- formative evaluation (continuous), which aims to point out weaknesses in order to improve future performance. The most suitable examples of the teacher's formative evaluation are observations made during the students' work within the education process or the evaluation of communication while solving a given task or during group work. Formative evaluation aims at the change of the evaluated subject and only then at the performance, and it generally has the form of a dialogue. 
- summative evaluation (final) - but only in the form of verbal evaluation (for more on verbal evaluation please see subchapter 4.1 The process, methods and forms of educational evaluation) and if all the characteristics of development evaluation are met.

Development evaluation is also important for the students because it teaches them to acquire competences in three areas (Porubský 2000, 6). Firstly, they will learn to evaluate themselves, and by creating appropriate conditions and incitements the teacher helps them to create a positive image in which they establish development goals by assessing their own attitudes and skills. Then they learn to evaluate the world, again with the help of the teacher applying interactive teaching methods for students to analyze and assess the information they receive. Students evaluate the attitudes and behaviour of others and interpret their own views and opinions. They also learn to reflect on the evaluation by others, and this is when students learn to understand the evaluation aiming at their personality, accept it as an incentive from classmates, teachers and family for own selfdevelopment.

We would like to finish this section with a thought by Kostrub $(2008,9)$, which we believe has already been suggested by the content of the chapter. "The teacher's perspectives of viewing the teaching process, the process of learning, the development of students and the whole education process are configured throughout the whole time of each teacher's professional experience." 


\subsection{THE FUNCTIONS OF EDUCATIONAL EVALUATION}

According to Turek $(2008,340)$, the main essence and function of evaluation is its diagnostic function, which is aimed at determining the extent of students' knowledge, skills and habits, and other significant qualities of their personality. The importance of the motivational function of evaluation lies in the fact that it has the potential to move students forward, help them to achieve success and positive appreciation. If during the education process students are motivated mainly by means of assessment, it may happen that evaluation becomes the aim rather than a tool for achieving the aim. The function of feedback in evaluation lies in the teacher's providing feedback to students on their performance, learning activities and the efforts made to perform the task. However, evaluation also fulfils an informative function, particularly in terms of providing study results to students and their parents. Evaluation in education sometimes functions to regulate student learning activities. If teachers formulate views on students, direct activities and draw attention to errors or incorrect procedures, they use the potential of the regulatory function of evaluation. The regulatory function therefore assumes a detailed analysis of student performance, including focus on the students' learning styles and methods, and providing assistance in solving possible problems. By fulfilling its regulatory function, the process of evaluation also completes its educational function because it leads (or should lead) to the formation of positive personality traits, such as independence, responsibility, persistence, which students can apply in relation to their surroundings as well. Here it is possible to mention the development function of evaluation as well (Turek 2008, 340), particularly in terms of developing the 
student's ability of self-control and self-evaluation. Very closely related to the development function is also the prognostic function of evaluation since evaluation has the potential to determine the students' perspectives, the possibilities of their further development, and who they can become and under what conditions (Turek 2008, 340). The conative function of evaluation means tending towards an active effect on the student. Above all, it is related to the basic human will to act and through this function students are guided through the activities they are performing while also being offered a selection of the most appropriate routes taking them to finish (Sršníková 2011, 20). Based on research, Petty (1996) argues that teachers should emphasize the efforts and persistence of students because it increases the effectiveness of teaching. Students should learn to evaluate themselves, consider their goals realistically and mainly to be able to assess how their own performance depends on their efforts: deciding when to attempt to reach for a higher purpose and when to stay on the ground just yet. If we want to achieve such a state, it is necessary to focus our attention on the way the student works and not his or her personality. The differentiating function of evaluation is the separation of students into homogeneous groups, for example on the basis of their school performance, the level of their communicative competence or pace of work. In education, the teacher can use the results of such evaluation in planning and prepare activities of various difficulty levels for individual students. The differentiating function of evaluation may appear at schools also in a negative sense, for example when the criterion of creating classes is the academic success or failure of students. Negative charge is also carried by the selective function of evaluation, especially when the results of school evaluation absolutize, namely when it disables a student to apply for study in a selected school. 
When implementing educational evaluation or control, the shortcomings may also appear. Educational objectives in most cases are general and vague, i.e. we cannot determine unequivocally the "ideal state" to be achieved. We do not know clearly what is to be regarded as the result of the education process: knowledge (i.e. memorizing and understanding information), skills (specific and non-specific transfer - the application of knowledge) or abilities as well, for example the ability to learn, or also the attitude, the student's effort, perseverance, etc.? If yes, then what should be the ratio of these elements represented in evaluation? We do not exactly know the answer to the question what to measure, therefore its validity (weight) is difficult to assess. Although marks are there at our disposition to evaluate students' performance, it is not clearly defined what two or three, etc. really are. In addition, student performance is not constant, but on the contrary, it is time-variable. We do not know how often to classify and evaluate the student for his or her assessment to be reliable (accurate). Thus, we do not know the correct answer to the question "How to measure it?" either. The consequence of these factors is the subjective evaluation of students.

If evaluation is subjective, it tends to be unfair resulting in the fact that the student does not agree with his or her assessment. In this case, the teacher's control and evaluation do not fulfil their functions, including that of educational, motivational and prognostic. It often happens that students who did very well at school do not succeed in life as much as their classmates with generally weaker results. One reason for this contradiction is the difference in evaluation criteria in school and practice.

The teacher's duty is to develop such skills of students which enable them to perform well in life, i.e. the ability to think for oneself, make decisions, take action and learn. Therefore, the 
teacher should not only examine the outcome of the learning process but also the learning process itself. After all, the development of learning skills should be one of the main aims of the school.

It is known that many students prepare for the lessons (they learn) the way their teacher is going to test them. Many teachers, however, direct testing to a lower level, mainly to remembering information (facts, formulas, definitions, theories, etc.). The result is that students prefer memory learning.

The assortment of the functions of evaluation is far from being unified and complete. Therefore the classification of Golnhofer (2003) was particularly inspirational for us, mentioning five evaluation functions according to the purpose they fulfil in the education process: the development-formative function, the function of feedback, the informative function, the function of greater efficiency and the differentiating function.

\subsubsection{The development-formative function of educational evaluation}

Here we will consider how we can positively affect the personality development of students through evaluation. Evaluation is an immanent part of the life of each class which we view as a social group with existing relationships and interactions among its members. Through positive or negative reinforcement the teacher evaluates the performance of students, their behaviour, attitudes and opinions. The development-formative function is achieved through building a positive self-image, positive social reinforcement, student motivation, and we also present the modelserving function of evaluation. 


\section{The function of building a positive self-image}

Self-image tells what the student thinks about himself or herself. It can have positive as well as negative content. It is exactly the teacher's evaluation that matters greatly in moving the students' image of themselves in the correct direction. Students differ in perceiving themselves, and it appears mainly in their preference of different opinions, attitudes and values. According to research results (Tóthová, 2001, 101), students with positive self-image do not attach importance to those school situations which are less significant from the aspect of their preferences. Conversely, students with negative self-image overestimate failure at school, which only reinforces their negative perception of themselves. Students with a positive self-image and realistic self-evaluation demonstrate a higher degree of motivation; they overcome minor obstacles at school more easily, achieve better performance in cognitive areas and is cooperating. Negative self-image and negative self-evaluation makes it hard for the student to adapt to school and later to society, and are obstacles to the positive development of his personality. The primary school level here has an irreplaceable place, because at a later stage, when the student already has a clearer vision and value preferences, building or renewing a self-image is hard to start with and correcting a negative self-image is very difficult.

If the performance of the student meets the expectation of the teacher, the student achieves success, while if the performance is below average, he or she feels and experiences failure. The chain of these sequences will affect the creation of the student's motivational aspirations and self-esteem. Likewise, evaluation is also influenced by the level of the student's self-evaluation. 
Self-evaluation is thus at the same time the cause and consequence of success or failure, it predetermines what attitude the student takes (a favourable or unfavourable one) towards fulfilling the tasks and obligations of school.

\section{The function of positive social reinforcement}

Reinforcement means that positive assessment assumes the repetition of a student's good performance. Reinforcement can be internal or external. Inner reinforcement is characterised by the external factors not being in operation. Activities and their good outcome already carry an affirmative effect in themselves for the individual. External reinforcement (rewards, punishments) occurs when internal reinforcement does not work or if there is a contradiction between the teacher's expectations and the values or performance of the student. Positive reinforcement (praise, recognition) in evaluation, when the teacher expresses satisfaction with student performance, is much more motivating than negative reinforcement. This may even have an impact on the social status of an individual in the group.

\section{The function of motivation}

Evaluation affects the motivation of students, their attitude to school, study obligations, the given subject or the teacher, and therefore it is one of the major motivating factors. It affects also the creation of students' learning styles. Tóthová $(2001,102)$ argues that the experience of success, expressed by the teacher's evaluation motivates students for further work and study. On the other hand, the student's failure expressed by the teacher's 
evaluation motivates him or her less towards further work, and he or she may even completely lose interest in studying.

The teacher must handle evaluation with caution. Unrealistic and undeserved over-evaluation, the use of positive evaluation including reinforcement can lead to false illusions of success in students, which is not justified and has no real basis. On the other hand, exaggerated negative evaluation destabilizes the position of the student as an active learner and prevents him from the feeling of success, which then discourages him. The teacher faces a difficult task: evaluate realistically, the real performances of students with the need to highlight positive aspects, point out weaknesses in the student's performance and suggest courses of action for improvement. By evaluation, teachers should primarily follow the development of each student's personality and abilities. Therefore, they should use evaluation as a means of increasing students' motivation to learn. This can help to achieve the student's increasing interest in learning, which is essential especially for the aims of self-development, permanent learning and self-improvement. The research results of Perry (according to Kovács, 2006) show that in those classes where students' self-regulation and self-development is taken into account, and the teacher uses interactive assessment throughout the whole teaching process, the students' errors are interpreted as a tool to improve performance. On the contrary, the students of the class where stress is laid on the quantitative parameters of achievement levels or the mystification of correct and incorrect answers, where convergent tasks prevail and the performances are constantly compared not only to standards but also to other students, are not lead to self-improvement and evaluation cannot fulfil its developmental role. 
The motivation of students is one of the determinants affecting the education process along with other factors that are likely to influence it, including for example the family background, the society and environment where students spend their free time, certain health conditions, etc. As it can be seen, there is indeed enough of these determinants, while each of them is capable of - either alone or in combination with other factors - affecting the intellectual and education process and hence the students' evaluation and marks.

The evaluation of learning results, classroom work, practical skills and habits acquired during practical instruction can be expressed not only by the teacher's giving a mark, but also by words, movements, gestures, facial expressions indicating acceptance, approval, satisfaction, praise, possibly disapproval, etc. The evaluation of practical performance, if it is a positive one, can enhance the student's confidence, but in case of negative results it can also help learners to correct their errors or deficiencies. The relationship between teachers and students within the evaluation process has a great influence on forming the students' self-esteem, self-confidence and not the least their character.

Evaluation of the results of the teaching process for individual students can be expressed also in the form of a mark reflecting the level of the students' knowledge, their habits and skills. In practice, the most attention is often drawn to the mark itself as it can determine the position of the student in the class, the relation of parents not only to the achievements of the student, but in some cases also to the student himself or herself. For many, the mark is the main motivation for learning, its sole purpose.

It must be noted that an experienced teacher should arouse the students' interest in learning, in acquiring new knowledge and 
practical skills so that students would have pleasure and interest in learning while overcoming difficulties step by step and inventing new methods for learning. Such intense intellectual activity, and not only during the lesson, but also when doing homework, would bring them joy, satisfaction and encouragement to gain further knowledge and solutions for their problems. It can be stated that students' aroused interest in learning or the learning material is the best motivation for them to learn; when the role and importance of marks is moved into the background and the sense of learning is found in completing tasks and acquiring new knowledge, which in turn can lead to solving complex tasks that previously were considered unsolvable.

\section{The model-serving function of evaluation}

By his professional approach to evaluation the teacher should achieve that evaluation could serve as a model for students' selfevaluation (autonomous evaluation) and peer evaluation, that is the one from classmates (for more, see section 4.1.2.2 Alternative methods of evaluation). For this, clear criteria, rules, forms and methods of evaluation should be specified. Marking the student's performance has little and very relative information value. Although the student's performance is associated with certain classification, this is not indicative of his or her qualities concerning personality, motivation and attitude. This negative phenomenon can be opposed by verbal evaluation which gives teachers the opportunity to express (verbally or orally) the strengths and weaknesses of student performance. The teacher can point out the student's diligence, the progress in cognitive areas, changes in personality traits, and the expectations of the teacher can also be outlined. For 
students, however, this system of criteria must be clearly legible, by which the teacher as well as students guide themselves and which they follow when being evaluated.

The teacher's evaluation affects the overall perception of the classroom atmosphere. If students perceive that the teacher's evaluation is not objective and it arouses negative emotions in them, this is reflected also in the overall social atmosphere of the class, in the nature of human relationships. And this is because the teacher is focused on negative assessment, on pointing out the mistakes in student performance. Students tend to imitate the behaviour of their teachers, they are often overly critical and unfair to each other, even negatively tuned, which does not favour positive classroom atmosphere in any way.

\subsubsection{Educational evaluation in the function of feedback}

Feedback can be understood as an information link between input and output, the effect of the controlled process on the controlling subject and also as the principle of the mutual influence between the subject and the object. (Obdržálek - Horváthová et al. 2004). According to Uhereková $(2008,11)$, feedback provides information on the quality of the education process for the teacher and the school management as a whole, constituting a mechanism to verify this quality and the students' acquisition of the curriculum.

During evaluation, a relationship is created between the purpose, the process and the output (results). The examination of the relationship between these elements assumes the possibility of entering the course of action with the aim of its optimization and continuous correction. The teacher makes plans, implements the 
process and guides student learning activities. Therefore, for his or her teaching activities to be effective he or she must constantly compare the achieved results with the set objectives. We call this process feedback. During feedback, the teacher compares the student to himself of herself, thus evaluation determines whether and in what extent the student shows a tendency for development, and also points out if the level the student achieved corresponds to standards. The implementation of feedback is a permanent process which makes immediate intervention possible for the teacher in case of recognizing (detecting) any deviations. This is when the teacher reviews his teaching methods and procedures, and adapts them so the set objectives could be achieved. It would be wrong not to notice and underrate these deviations because ignoring them could cause serious deficiencies in student development and not only in the cognitive area. So that evaluation could fulfil the function of feedback, it is necessary to carry out a diagnostic evaluation at the beginning of the school year to determine the current level of the student's personality development. Any further evaluation during the year helps to monitor the individual student's progress in the measured parameters of his performance.

\subsubsection{The informative function of educational evaluation}

Information on evaluation results can be helpful in recognizing problems in learning and behaviour. Regarding the informative function of educational evaluation Gavora $(1999,11)$ refers to the diagnostic information. He claims that it is intended not only for teachers but also students and we add that for the parents (and other subjects) as well. The teacher informs the student and his parents 
on the student's state of development. By evaluation, the teacher informs the student and his parents about the achieved results stating whether it meets the teacher's expectations or if the teacher is happy with it. For the needs of the student's development it is ideal if this information is forwarded to the student and his parents by the teacher in the form of regular reports on the student's progress. Parents can help their child to overcome failures and obstacles, and together with the teacher influence and motivate him positively for further work. Thus, the evaluation can fulfil the above-mentioned functions as well, like that of motivation, reinforcement, creating a real self-image and more. This way of transmission is obviously not possible without the mutual trust between teachers and parents, the two-way communication and collaboration.

The student must be aware of the details of why his results are satisfactory, why unsatisfactory, which is a realistic precondition of his further successful progress. This is only possible if the evaluation is objective. The objectivity of evaluation is meant to be ensured also by verbal assessment, through which the teacher specifically in proportion to the student's abilities communicates the results of his or her work in various evaluation segments, highlighting strengths, pointing out weaknesses and the opportunities for development.

The results of evaluation are good and valuable sources of information for teachers themselves, who alone have the option, based on the evaluation results, to make corrections in the process of teaching and learning.

Who should be informed about the results of evaluation? Gavora $(1999,11)$ names the following participants: the headmaster of the school, teaching staff, educational adviser. The recipient of educational information can also be the school psychologist, the 
founder, school of a higher level, employment organizations or the society. In mediating information on evaluation results it is taken into account who is involved in the process and the purpose of evaluation is also regarded. For example, when evaluating the results of a specific subject through an achievement test the evaluation may concern:

- the student himself who cares about the score he received, what he knew and what he did not, where he made a mistake,

- the teacher of the given subject who wants every student to stand the test well,

- the creator of the test who wants to know the validity and reliability of the test,

- the parent whose primary objective is to make the child succeed in school,

- the headmaster whose interest is to preserve the good image of the school and increasing its quality,

- the founder who is interested in the continuous quality improvement of the school in his scope of operation.

\subsubsection{The function of greater efficiency in educational evaluation}

Evaluation results tell us whether the teaching, the school or the school system is successful and efficient. There are various parameters, criteria that tell us about the effectiveness and successfulness of teaching. Indicators of success may be the results of students in school-leaving examinations, the results of monitoring the knowledge and skills of students finishing the 4th and 9th grade of primary schools, the results of international 
measurements, etc. The wide application of achievement tests enables the comparison of schools with each other, based on the results of student performance, and if countries enter international measurements, the effectiveness and successfulness of the whole school system can be measured.

As a rule, the effectiveness of a school is assessed according to the number of students accepted for further study, the students' prominent positions in various competitions and their results in national measurements. These are manifesting indicators which, however, may not be representative of the actual quality of the educational work. After all, schools with good image, schools for which there is demand, schools with attractive study offers have no shortage of students. These students generally achieve not only excellent academic results, but are also engaged in various competitions more often and with good results. Latent, but no less important indicators of a school's successfulness are the added value of educational work expressed in the individual development of each student, the application of a uniform philosophy of education at the school, the cooperation of teachers in approaching students and following their development, the application of alternative and activating teaching methods to develop students' motivation and self-knowledge, and other factors.

To sum it up, it can be stated that the absence of clearly defined indicators measuring the quality of education both externally and internally also implies the inability to objectively evaluate schools which due to their specific conditions achieve outstanding results.

A serious problem is also manifested in the lack of clearly defined rules of such educational measurements which would reflect not only the immediate and the current level of the learner's 
knowledge, but it could track the student' progress throughout the learning process. The question therefore arises whether external measurements (Monitor) assessing a state of knowledge in two years of primary school (4th and 9th grade) in two subjects (Mathematics, Slovak, possibly the language of instruction) are truly objective?

\subsubsection{The differential and selective function of educational evaluation}

Children arrive at the school from families that acknowledge different values in education. The family environment where children come from is stimulating for them, somewhere more, somewhere less. The purpose of school education should be to overcome deficits in inspiration and perception that the child brings from the family to school, as it is claimed by Gavora (2003, 132). In reality, however, school assumes a certain intellectual and mental level (school maturity) for children from the beginning of school attendance. So children, depending on how they manage schoolwork, are differentiated and separated right from the start into smart and successful ones and those less capable. The less successful ones start to experience failure and they fail to recognize the feeling of a well-done job because they constantly lag behind in their work.

The differential and selective function of educational evaluation is oriented towards the differentiation of students based on their abilities, interests, possibilities of advancing to schools of higher education, the chances of gaining higher qualifications as a prerequisite for a higher position at work and 
the prestige associated with higher job functions (Obdržálek 1996, 21). It is often the subject of criticism. The school must create equal opportunities to access education for all. How the individual uses his chances will depend on his assumptions and hard work. The selection or choice is made at different levels of school education; it can facilitate the further career of individuals while for others this can be made difficult or completely impossible. It is implemented through testing and a certification process. The first selection takes place already at the threshold of school attendance, even when choosing the type of primary school, and then in transitions to other educational levels, for example on the basis of entrance exams, certificates, diplomas and reports. The way society looks upon the selective function of school is strongly influenced by the value that people attribute to individual occupations and professions, what prestigious scales prevail in society and what values the majority of population acknowledges. The differential and selective function of educational evaluation in a sense is also confirmed by law NR SR 324/2012 Coll., solving the admission of students to the first year of secondary school studies: if their academic average does not exceed 2.0, the admission into four-year grammar schools and for five-year bilingual studies is allowed, and if their academic average from compulsory subjects at the end of the second term of the prelast year of study and the first and second term of the last year of the primary school do not exceed the average of 2.75 , the admittance to secondary vocational schools is assured. 


\subsubsection{The teacher's attitude to students and the methods of evaluation}

Evaluation and classification are the result of testing students, which should be approached by every teacher particularly tactfully in view of the nature and the psychological development of the student. The evaluation of students should be handled responsibly by the teacher as an experienced educator with full level of dedication and concentration. In general, the teacher's operation can be considered pedagogically tactful if the controlling and educating functions of testing, marking and evaluation are balanced and do not discourage students to continue learning, but rather motivate them further to acquire more knowledge and experience.

Every teacher should impress their students with their teaching skills and the ability to generate motivation for learning. The teacher's attitude to students, the way how the new material is presented, how the lessons are managed or the instructions in practical exercises are demonstrated, often lead to the situation that even those students who so far had shown no interest in a particular subject or lesson start to learn, ask questions and request additional information. In other words, by the open and friendly approach of educators to students, students feel motivated and try to prepare for the lessons more thoroughly and honestly, which obviously has a direct impact on the subsequent evaluation of results. It is then also possible to suggest that a certain chain is created when the student due to the motivation by good evaluation (which was the result of his good answers or scores) begins to learn by himself on a regular basis in an effort to get good marks again. Thus, the student is motivated, which is extremely important in the education process. 
At the same time, it is also necessary to keep in mind that each student responds differently to the mark or the result of evaluation regardless of the way it was carried out. For the student with good learning and practical results a worse mark can act as a stimulant, but also as a deterrent reflected in his refusal of studying. Similarly, if the student with not so good results gets a better mark, the effect can even be negative, because he may think that a better mark was given to him at random or out of pity, as a result of which he may lose the appetite for learning and then if consequently he gets a worse mark he will be discouraged again. To avoid the above case, the teacher should be giving marks objectively and evaluation should reflect the true, real level of student' knowledge of the subject required by the curriculum. This means that differentiating in evaluation is an important part of evaluation requirements and learning results should be evaluated from different aspects and in different ways.

The evaluation of students' learning results should also meet the requirement of adequacy. Each student should know and mainly understand the reason behind receiving a certain mark, because only in that case will the mark as one of the ways of evaluating knowledge be a means of improving the student's relationship to learning and the acquisition of new knowledge, habits and skills. Accordingly, it is appropriate and recommended for the teacher to explain to the student orally or in some cases even in writing why that particular mark was given to him and to explain all the positive and negative aspects of his performance indicating what direction his further learning should take.

When the teacher evaluates a number of tasks that the student had worked on during the whole lesson, the process is called whole-lesson marking. Whole-lesson marking is for some students 
more significant or acceptable, because here the less appropriately or adequately completed practical tasks can be corrected, either by a more detailed explanation, an additional task or even by accomplishing a different task, which will show to an experienced teacher that the student understands the given subject matter, masters it and is able to apply the gained knowledge in practice. Whole-lesson marking thus motivates students throughout the whole lesson of practical education to respond and be active.

The activity of students is of great benefit to the education process, and not only to students. For some teachers, achieving the activity of students is almost impossible even after twenty years of teaching experience. In other words, the teacher's approach to students and the ability to arouse their interest in the task so that they initiate discussions on the lesson all by themselves is the best motivation for them.

As stated above, the evaluation of students is an essential part of the diagnostic process; it means the assessment of students and is present in all communication between teacher and student. The consequence of the student's reply is the reaction of the teacher - the teacher may praise the student and award his response with a mark, the student may be asked for completion or submitted to criticism, etc. Nevertheless, the reaction of the teacher can also be non-verbal communication - a smile, wagging a finger, etc. This is an indicator of the teacher's satisfaction or dissatisfaction with the student's response. The student's performance (the response) is assessed in comparison with certain criteria, thereby maintaining the objectivity of evaluating the student's intellectual and practical skills. This criterion in most cases is given explicitly and is unchanging (e.g. in the curriculum, education programmes or other educational documents). For the teacher, criteria are 
significant aids in evaluation. Curricula in most cases quite precisely indicate the cognitive targets (knowledge and skills) that the student must be able to handle at the specified school age. Affective objectives, however, are set out in rather general terms (e.g. the student's attitude, interest, motivation).

\subsection{THE DIMENSIONS OF EDUCATIONAL EVALUATION}

By analysing the objectives and functions of educational evaluation we have arrived at the definition of the dimensions of educational evaluation. The reason for this is the fact that the problems of educational evaluation, the process itself, its means and methods can be examined from different points of view.

Learning results express how quickly and thoroughly the students are capable of using the knowledge, skills and abilities acquired during school instruction and if they can apply these on other lessons, in their further studies or their personal, professional life.

The function of evaluation on the lesson is the expression of the quality of learning results, the evaluation of changes or shifts that the individual achieves and the provision of this information to teachers, students and their parents. The aim of evaluation is also to build an effort to positively influence factors affecting the academic performance of students. It should be noted that evaluation for students is an expression of their achievements, but it also affects their further learning progress. Evaluation can have a motivating as well as demotivating effect on studying. Therefore it is clear that students themselves should be interested in evaluation and be familiar with its criteria and rules. For teachers, evaluation has an 
informative character and is the basis for analyzing the results of teaching, and the reason for changing or keeping certain methods and techniques of guiding the process and the students' learning activities. For parents, evaluation results may be contradictory especially if the expectations of the school and the parents are not in conformity with each other.

\subsubsection{The social and personality dimensions of educational evaluation}

The essence of personality lies in the coordination of experience, behaviour and social perception, by increasing the level of knowledge and the formation of one's mental properties and that of other members of the community, states Manniová (in Horváthová-Manniová 2008, 154). The acquisition of positive personal characteristics that schools strive to achieve mainly happens through social interaction, which is reflected in the quality of the individual's relationship with other members of the community as well as in the individual's behaviour towards them. Features of personality are closely related to the individual's interpersonal and intrapersonal competences. Intrapersonal competences of the personality are those complex activities of the individual which focus on oneself and one's own development. This is for example self-knowledge and self-understanding, forming the basis of self-evaluation which is represented in the assessment of one's own abilities, beliefs, characteristics, motives and behaviour. Self-motivation, which means the conscious mobilization of one's own abilities and directing them to certain specific goals, makes the individual capable of self-management 
which determines the strategy of activities to hit the chosen target. The individual's main interpersonal competences include social perception (in relation to others) and communication. If we talk about interpersonal competence as one of the personality competences in the field of social perception, besides knowledge we also mean the complex of those relations and attitudes which enable perception and the knowing of man by man (Manniová, in Horváthová-Manniová 2008, 158). Social perception at school is a way of social cognition, influenced by the social environment of the school and depending on life experience and currently by the rate of being informed as well. Social interaction, social relationship and its perception occur through communication. Verbal or non-verbal communication and intentional or spontaneous communication express the relationship between the main participants of the interaction.

The expressive aspects of verbal, non-verbal and metacommunicative contents expressing the dyadic relationships of individual - individual, individual - group and individual society are of concern to the personality dimension of educational evaluation. The main function of verbal evaluation is to regulate the behaviour of students through positive social reinforcement, rewards, motivation, or on the contrary, by penalties and disincentives. This context also allows the examination of specific features, respectively dilemmas of educational evaluation caused by subjectivity or just the opposite, the efforts of objectivity, the teacher's preconceptions, the halo effect, the teacher's personality, etc. What is important is how the evaluation results of school performance are experienced and decrypted by students of different ages and their parents coming from different sociocultural conditions, and how it affects the students' course of 
learning. As Kolar and Šikulová noted (2009, 55), evaluation verdicts and their possible social consequences affect the ideas of families on the prospects of their family members and also allow the inclusion of families in the social hierarchy. This aspect is therefore undoubtedly a thesis of the social dimension of educational evaluation.

\subsubsection{The didactic dimension of educational evaluation}

Evaluation is the process through which it is possible to find connection between the set targets and the achieved results. In this process, evaluation provides information on the extent of the achieved goal. The aim of evaluation is to optimize the process of teaching and learning through the function of feedback. In connection with the didactic dimension, the question arises whether the results of educational evaluation are applicable, especially at a time when the social value of education is changing.

\subsubsection{The social dimension of educational evaluation}

The permanent enrichment of the functions of evaluation is a general social phenomenon. It is caused by socio-political changes, the development of pedagogical and psychological knowledge, the development of science and technology, and the application of research findings in educational and didactical practice. 


\subsection{NEW METHODS OF TESTING AND EVALUATION}

In addition to traditional testing methods such as oral tests, achievement tests, the assessment of various written works (graphic design, projects, protocols of measurements, etc.), at present other methods of testing and evaluation are applied as well, in particular:

One of the current trends in student evaluation is the introduction of the so-called portfolio in which the teacher can store the student's works systematically and for a long time (midterm and final achievement tests, protocols of measurements, drawings, projects, reports, essays, the teacher's records of the observed student, the results of interviews with students, selfassessment sheets of students, messages and notes of parents, etc.). The teacher thus has the possibility to follow the direction, the nature and degree of changes in the student's learning. The portfolio should also enable students themselves, their parents and other interested participants to get the fullest possible insight into how the student learns and thinks, how he or she creates technical or other artefacts, how he or she behaves with other people, etc., that is the various components of the student's personality, interests and talents. The portfolio allows the student to succeed with different learning styles. The portfolio is evaluated in an interview when the student answers the questions of the examination committee relating mainly to the explanation of portfolio items, defending their accuracy, etc.

The type of testing where students are allowed to use any literature and aids (in English: open-book exam) is also widespread. Such testing is focused mainly on higher cognitive processes such as analytical or critical, creative thinking, the ability to solve problems, the ability to acquire and use information, etc. 
At present, authentic learning and the authentic evaluation of students is a very current trend. The teacher organizes the teaching process in a way so that it could be comparable to the real world and life as much as possible and students could apply the subject matter of instruction meaningfully, for example creating something that brings joy to themselves, their parents, friends or other loved ones, and the community. With authentic evaluation the artificial school task is not assessed (e.g. the exercises of an achievement test), only the student's performance, which is meaningful even outside teaching, out of the school. For example, it is not enough if the student describes the general phenomena of the electromagnetic field, but he could be able to design an operating front door bell. With authentic evaluation it is not sufficient that students merely reproduce the curriculum, but on the contrary, they must search for information, interpret them, analyze, produce, create, explore and solve problems related to the subject.

The students could also be involved as partners in the evaluation process. For example, they can correct and assess educational tests themselves according to predetermined criteria which can be formed with their and the teacher's involvement. Such a procedure has an educational impact as well, forming various character traits of students, such as honesty, fairness, persistence. It is also appropriate from time to time to carry out a discussion with students focused on testing, evaluation and marking. One of the current trends is also students' self-assessment and their assessment of other students, called peer evaluation. Both of these evaluations are taken into account in the final evaluation. For example, a student will first evaluate his response alone (essay, oral report, etc.) then it is assessed by his classmates and eventually by the teacher who compares and considers the student's self-evaluation, 
his/her own and the evaluation of classmates. Students thus learn to evaluate themselves, to value other people, objects, processes and the phenomena of the surrounding world and to receive and reflect on the evaluation of their person from others.

The formative evaluation of students is advised to use in a much greater extent. The aim of formative evaluation is feedback, acquiring information on how students learn, detecting and diagnosing weaknesses, mistakes, difficulties and their causes in the process of learning in order to eliminate them and make students' learning activities more efficient. For the teacher, feedback helps to choose the optimal teaching practices. Formative assessment did not use to be associated with the marking of students. Formative assessment is often identified with students' continuous testing and evaluation, which is a mistake because in continuous evaluation the subject matter of one or more lessons is assessed, the causes of deficiencies are not detected and the student is not usually informed of these deficiencies, nor on how to eliminate them and make the learning process more efficient.

Verbal evaluation of students is also widely used complementing the marking process or even replacing it. It is very difficult to assess students' attitudes, interests, their value system, talents, skills and core competences with a mark. The biggest disadvantage of verbal evaluation is that words can be ambiguous. Verbal evaluation is more laborious than the evaluation with a number, as the teacher must invent a verbal assessment for each student, plus pay attention to avoiding its repetition. Therefore, the tendency is to combine number-based evaluation with verbal evaluation. Verbal evaluation, the so-called student profile should include in particular:

- the student's interests, special skills, talents, 
- the quality of the achieved results,

- moral and personal characteristics, diligence and conscientiousness,

- activity and independence,

- the understanding of spiritual values,

- the level of the student's key competences (how he can study independently and rationally, what his relationship is to learning, the ability to solve appropriate problem tasks, the level of critical and creative thinking, communication skills, personal and interpersonal competences, e.g. the willingness to help others, respect, courtesy),

- the level of knowledge and skills of the student,

- behaviour, respect for educational and social requirements,

- aesthetic expressions and aesthetic sense,

- the protection of material values.

In vocational training there is a tendency for testing and focusing evaluation on acquiring the relevant professional and key competences, and achieving the appropriate standards. Evaluation is often external. Not only teachers evaluate students, but vice versa, students also assess the quality of teachers' work through anonymous questionnaires. The humanization of students' evaluation is based mainly on trending towards the progress in their development, detecting and evaluating changes in their attitude, skills and knowledge, compared to a previous state, and the students themselves at the time. It is thus about the individualization of the student's evaluation. Comparing the student's performance with the standard is subordinate here and is implemented through tests to verify the achievement of 
the required educational standards. The aim of the humanisticoriented evaluation of students is to develop their self-assessment skills.

\subsection{AUTHENTIC TEACHING AND EVALUATION}

Another trend in teaching and evaluation is authentic teaching and the students' authentic evaluation. Not only in the past but even today quite often happens that students after finishing school are not ready for real life and do not know how they should apply the acquired knowledge in practice. To the elimination of these shortages a new trend in learning could contribute - authenticity. Applying this trend the teacher prepares and organizes the learning process in such a way that the student does not only understand but also contributes to creating the work (or even creates it himself) that is needed in real life.

Authenticity in education contributes to a deeper understanding of the curriculum and its point in real life, making the lesson more interesting and varied. I. Turek $(2008$, p. 246$)$ states that in authentic evaluation it is not artificial school tasks, e.g. exercises in achievement tests, that are assessed, but students performance, which is meaningful even outside teaching, outside the school. Authentic teaching and evaluation is very close to practical teaching since students learn to apply theoretical knowledge in practice. 


\section{SUMMARY}

The third chapter The concepts, functions and dimensions of educational evaluation is divided into four subchapters: 3.1. The concept of evaluation in relation to the concept of education, 3.2. The functions of educational evaluation, 3.3. The dimensions of educational evaluation and 3.4. New methods in testing and evaluation.

In the subchapter titled 3.1. The concept of evaluation in relation to the concept of education, I dealt with the definition of evaluation which I characterized as a comprehensive view on the issue from the aspects of defining the process of evaluation, the application of methods and the means of evaluation results. I have defined five concepts of educational evaluation. The concept of competition in educational evaluation emphasizes results and ranking students according to their performance. I have briefly explained that the concept of competition in techniques and methods is pursued through the creation of the same strictly observed conditions for all and the existence of such rules and evaluation criteria that ensure their objectivity. It may be presumed that the application of the concept of competition is allowed the most by the traditional type of the education process, based on the behavioural theories of learning. I also pointed out the problem areas of this concept. At the centre of the non-competitive concept of educational evaluation is the performance of the individual who is carefully guided and individually commented, while the comparison of students with each other is consistently avoided. It is close to the concept of interpretive education. I pointed out the problem areas of this concept as well. The cooperative concept of evaluation is successful especially under the conditions of the 
autonomous concept of education and considers teachers and students equally responsible for the efficiency of the teaching process. A similar concept is the humanistic-oriented concept of educational evaluation, i.e. personality-focused evaluation where the criterion is the evaluation of the students themselves through accurate and specific expressions. The essence of the development concept of educational evaluation is based on developing the students' competences in three areas: self-assessment, evaluating the world and reflecting on the evaluation by others.

I have identified five evaluation functions according to the purpose they fulfil in the education process. Each function is presented in a separate subchapter. The developmentformative function of educational evaluation is the subject of the first subchapter where I was considering how evaluation can positively influence the development of the student's personality. The development-formative function of educational evaluation is realized through building a positive self-image, positive social reinforcement, the student's motivation and the model-serving function. One's self-image tells what one thinks of oneself. In this regard, inspiring for us were research results which indicate that a student with a positive self-image and realistic self-assessment demonstrates a higher degree of motivation, overcomes difficulties more easily and successfully and achieves better results in cognitive activities. Reinforcement means that positive evaluation assumes the repetition of the student's good performance. It is expressed mostly by praise, the recognition of the student's performance, which motivates him or her further to give a good and always better performance. The attitude to school, study obligations, the subject or the teacher also affect the student and takes part in forming his or her learning styles. 
I further pointed out that the teacher's professional approach should achieve that evaluation could serve as a model for selfassessment and peer evaluation. In the second subchapter I introduced educational evaluation in the function of feedback. Feedback is important because it provides information about the quality of the education process. During evaluation the relationship between the aim, process and results is realized through feedback. Examining the relationship between these elements is important because it allows the optimization of the course of actions and the results of the education process. The third subchapter is devoted to the informative function of educational evaluation which lies in informing the student and parents (but also others) about the results the student achieves and how these meet the teacher's expectations. The fourth subchapter presents the function of greater efficiency in educational evaluation. Here I critically noted that the absence of clearly defined indicators for measuring the quality of education on external and internal levels also means the inability to give an objective evaluation of schools which regarding their specific conditions are achieving good results. In the fifth subchapter I introduced the differentiating and selective function of educational evaluation, which is oriented towards the differentiation of students in terms of their abilities, interests, or opportunities to advance to higher-level schools and to gain higher qualifications. I pointed out that it is often the subject of criticism because our schools usually only deepen the social inequalities among students, are selective about them and the choice of school is often determined by the result of school evaluation.

By analyzing the functions of educational evaluation we aimed to arrive at defining the dimensions of educational evaluation that 
offer insight into the process, resources, methods of evaluation from different perspectives - the dimensions. In this context, I defined three dimensions of educational evaluation: the personality dimension, where the levels of relationships between the object and the subject of educational evaluation are examined, the didactic dimension, the aim of which is to optimize the process of teaching and learning through the function of feedback, and the social dimension, the point of which is to enrich evaluation with the achievements of modern science, technology and social relations. 


\section{CATEGORIES OF EDUCATIONAL EVALUATION}

The chapter of Categories (types) of the teaching evaluation will focus on the pros and cons of different types of educational evaluation and its impact on the development of students' personality. We highlight the fact that different types of evaluations differ from each other not only by their informational value feedback, but as well as incentives and conative consequences that follow from that information. In this chapter the subject of our analysis will be the presentation methods and forms of educational evaluation in relation to each stage of the evaluation process. In order to score efficiently to fulfil their functions and, ultimately, to make it a means of shaping the student's personality it is necessary to emphasize another important aspect which can also help increase the objectivity of the evaluation, and this is the presence of setting clear, pre-agreed rules of evaluation, definition, which we will be paying closer attention to in the second subsection. In the third subchapter, entitled The micro level of educational evaluation - the state of research problems, we present a number of research evaluations at today's schools and their results in terms of classes and students from various aspects of looking at the issue under consideration.

Depending on what function evaluation performs, at which stage of teaching it is applied and what volume of information for students it verifies, we distinguish these types of educational evaluations: diagnostic evaluation, formative evaluation, summative (final) evaluation.

The purpose of diagnostic evaluation is to reveal the current status of entry-level skills not only of individual students, but also 
the whole class, and the social relations between students, as well as learning difficulties and problems of students. Disclosure of these facts allows the elaboration of strategies for education and training, which will be based on the distinct needs of an individual or the whole group, proposes Lappints $(2002,277)$. This type of evaluation is useful for us, as on the basis of its results we may decide on the degree of differentiation in the group, add the missing information, knowledge, focused on building the necessary competencies, springs Bóta $(2005,197)$. An experienced teacher, as formulated by Gavora $(1999,29)$, then relies on the results of diagnostic evaluation and proposes the planning and management of teaching throughout the school year.

The essence of formative evaluation is to provide feedback to teachers and students to underpin further effective learning of students. Based on this evaluation, the teacher makes a correction, solves problems of teaching students or, conversely, takes measures to build on the positive results (Gavora 1999, 30). This procedure can avoid students' lag in performance or achieve minimization of the difference in performance. In a classroom, formative evaluation mainly fulfils educational and motivational functions; it helps the teacher in shaping the personality of the student in a respectful manner. Formative evaluation in the educational process for the development of student's personality is considered extremely important and necessary. According to Štulrajterová $(2008,48)$ it lies in the fact that the teacher verbally evaluates student performance, learning progress over time, and does not compare his/her performance with only the norm, but also with the student's potential or past performance. The teacher undertaking the formative evaluation firstly depicts what the student has proven what was positive in his/her performance. He 
informs students about what and how to improve, what direction to aim their further activities. Such an evaluation should be concise, understandable and comprehensive, so that it stays informative and positively motivating for the student. Formative evaluation, in the opinion of Štulrajterová $(2008,48)$ does not preclude classification. The student can get a grade as well as a formative evaluation; however these may not be in agreement. Formative evaluation can be very positive if the student who provides average performance is extremely studious and diligent. Conversely, if a student who has great potential, but is lazy and uncooperative, and does not adequately use his/her skills, receives negative formative evaluation. From formative evaluations the student learns about evaluation criteria, of the remedies as to what $\mathrm{s} /$ he should focus on in the future as to improve. Formative evaluation allows students to experience success and a sense of self-worth, especially those students who may never be included in the top performance groups in summative evaluations. Experiencing success stimulates students' affection and relationship to the subject, and the relation to oneself. While the summative evaluation classifies performance and allows them to be compared, formative evaluation emphasizes the learning process and leads to a subsequent optimization.

Summative evaluation determines the level of knowledge achieved in a specified time period. This evaluation is also termed final, as it summarizes and recapitulates what the student has learned and what properties s/he acquired (Gavora 1999, 31). Summative evaluation is also referred to as final evaluation (eg. Štulrajterová 2008, 49) that can satisfy the principle of formative evaluation, but only if it assesses the personal growth of its students (attitude to learning, learning behaviour, individual traits, 
tendencies, interests), while denouncing the achieved results, says Bekéniová $(2006,12)$.

With summative evaluation student performance is compared with social norms, population norms or criterion and is usually also expressed formally, for example with classification in figures or words, letters, or the number of points or percentage. In this type of evaluation we create groups of students according to their level of required achievements. Selective evaluation functions are thus filled, which by their nature can influence the decision of the student on his/her professional career, a choice of further study as well as deciding on the adoption of a student for this study.

Because these moments are crucial in the life of an individual, while determining and assessing, the teacher must approach them with maximum responsibility and seriousness. In addition, it is necessary to note both positive and negative aspects of the summative evaluation. The good thing is that it is short; therefore it does not encumber the teacher. On the negative side, it compares the students with each other, and as Štulrajterová (2008, 49) stressed, it can cause unhealthy rivalry and inferiority complexes in the average student.

In the previous context, the presented concept of formative and summative evaluation was conducted in accordance with a key that has a different level of sophistication in the provision of evaluation information. Formative evaluation looks at how a quality evaluation of student performance can be used to form and perfect a certain practitioner's competence. This means that formative evaluation focuses on the process of evaluation, using feedback to serve students. On the other hand summative evaluation focuses on product outcome. 
According to a key which is a measure of exercising the functions of educational evaluation, we may view a mainstream of a horizontal or vertical cut. In applying horizontal section bipolar definitions crystallize that teaching literature identifies as bipolar types of evaluation (e.g. Buda 2013): cognitive and humanistic, analytical and holistic, quantitative and qualitative, Kolar and Vališová $(2009,180)$ add thereto negative and positive evaluations as well, furthermore, we also complement the normative and criterial evaluation. These types of evaluation can also be seen as mutually contradictory or conflicting.

Cognitive evaluation focuses on the evaluation of cognitive performance of students' knowledge, thereby enhancing the selective function evaluation. The extent of adoption of curricular content is evaluated. The humanist evaluation focuses on the process, taking account of specific conditions. It allows capturing subtle semantic differences in the individual areas of student performance.

The analytical evaluation is based on an evaluation of performances, using well prepared evaluation schemes or scales, which generally involve an evaluation of all essential components of the exercise (e.g. When writing an essay grammatical and stylistic accuracy is particularly valuable, clarity, relevance of content; dictation is determined by the number of spelling errors, etc.). Learning outcome (product) is separated, segmented into clearly distinguishable elements to be evaluated. Performance is usually attributed points; respectively other numeric or alphanumeric values (Gavora 2010, 153). This evaluation procedure is acceptable in the context of the process of learning because students have a clear idea on what basis they had gained a given grade, and for the evaluation no essential criterion had been omitted. Holistic (global) ranking is based on evaluation by the general impression. 
In this type of evaluation the student's result is not structured or divided into recognizable elements, but is evaluated as a whole, as it is explained by Gavora $(2010,153)$. Even as an impression evaluation, each evaluation is based on a more or less conscious of criteria which he considered to be the most important thing is that a number of evaluation criteria are not completely identical. In the favour of global evaluation it is true that the whole and the resulting effect of the work (e.g. essay, poem recitation, painted image, but also verbal responses of the student) is not merely the sum of the quality of individual parts. On the overall results of the portions do not contribute equally, in addition they share complex interactions and influence on each other.

Quantitative evaluation is both the process and the result, in which results are compared in a quantitative manner (quantity, number) and are expressed as a numerical value, or percentage. Quantitative evaluation in our schools has a rich representation, and the roots go back to a historically very remote period. Quantitative evaluation is deemed in our schools as a score with long tradition, which, let's face it, is very popular even among parents. The student performance classification it expresses satisfies the parent, who does not require the teacher to apply other types of evaluation. Qualitative evaluation lies in the fact that the individual power levels of a student are assigned a specific value. According to Pascha et al. $(1998,102)$, qualitative criteria related to higher cognitive process at the level of synthesis and evaluation of thinking. These criteria are evaluated by a more complex activity of students, which is often difficult because the teacher has to determine the minimum level of form, substance of performance or product of the student to be adopted. The fundamental difference between quantitative and qualitative evaluations to the cognitive 
area is, according to Kašiarová $(2009,5)$ that in assessing the performance level of remembering and understanding information the accuracy of the result is measured. At other levels in the hierarchy of performances, it is required to name the expected performance characteristics with other specific and concise terms or a complete sentence.

Negative rating means focusing on the analysis of errors and omissions in student performance. The teacher points to a lack of effort, the absence of personal intrinsic motivation and engagement resulting in shortcomings in performance. The teacher can also highlight the consequences of such conduct in further process development. The teacher can express their dissatisfaction with non-verbal means of communication, or paralinguistic aspects of speech (e.g. body posture, facial expressions, tone of voice), which multiplies the effect of the teacher's verbal expression. Positive evaluation does not mean that mistakes are downplayed or flaws being unnoticed, but that they will always be based on what was positive in student performance, behaviour and workflow, what the student has mastered, or proved. There is a wide range of nonverbal and paralinguistic expression means of communication available for the teacher for this type of evaluation of, such as caress, smile, gestures, and tone of voice and melody, which may express their satisfaction. The evaluation usually applies these two types simultaneously, i.e. at the same time, but in first positive and then negative rating order.

In standardized evaluation the performance of individual students is compared with the performance of others who perform the same function (Bóta 2005, 198). Teachers in this type of evaluation take into account the particular social relationship systems (frame), the most commonly the class. It means that in 
classifying, the student receives a grade depending on his/her position compared with other students. Sršníková $(2011,25)$ states that the result may be that the students may be dissatisfied with the outcome of the evaluation, as others may have studied just as conscientiously. Therefore, this evaluation is not considered righteous. Being the best student in an erroneous class or the worst in a decent class is not the same as in a medium performance class, notes Sršníková $(2011,25)$. In this type of evaluation a lot of very average and little very good, respectively very poor performances are to be expected. In the event of such an evaluation, students can study how much they want, which may lead to partial improvement in their skills and knowledge, but especially for their efforts to increase their rating, which will ultimately have a very bad effect on their motivation for learning activities. With criterial ratings the measurement device for the performance of individual students is the performance of a task, regardless of whether the task was fulfilled better or worse in relation with other students. This evaluation is often referred to as the evaluation of absolute performance. The classification of individual performances corresponds to whether the specific description of the performance (test) has been achieved, regardless of the achievements of the others. This means that all students who meet the criteria can succeed. Theoretically, applying this method of marking it is possible for every student to reach an 'excellent' grade. Given the fact that with criterial evaluation any number of students can be achieved any grade, there is no need to differentiate between them. However, the mark does not say whether the student learns better or worse than others. In other words, it reflects the performance, not the status in the class. Nevertheless, we believe that the motivation for this type of evaluation is higher, as per students do not have to compete 
for a limited number of available good marks, as is the case with normative evaluation.

In applying a vertical cut with defined types of evaluation we find ourselves at the level of recognition the distinguishing features of already mentioned summative evaluations (expressed in terms of cognitive, analytical, quantitative, negative and normative evaluation) and formative evaluation (expressed in terms of a humanistic, holistic, qualitative, positive, criteria-evaluation). In educational practice, while applying the types of educational evaluation, teachers are often polarized. On one side, there are those who advocate the need for summative evaluation and recognize it as a starting point of the overall evaluation process. They declare that summative evaluation needs to be first, and it is necessary to assess the quality of work before any feedback is given (Sršníková 2011, 23). On the other side, there are those teachers who oppose the summative evaluation mainly because many of the principles that are appropriate for the summative evaluation cannot be applied in formative evaluation, which requires distinctive conceptualization and technology (Sršníková, 2011, p. 24). The fundamental problem of educational evaluation is certainly not in the plane of summative versus formative evaluation. I share the opinion of Koláŕ, Vališová (2009, p. 177), who see the substance of evaluation in the kind of function evaluation will perform in the classroom, as how evaluation will contribute to the personality development of all students. Sršníková (2011, p. 24) further develops this tendency when she asserts that in the classroom, it is necessary to support efforts of teachers to find a way to ease tensions between the two methods of evaluation. One of the solutions to achieve the desired state is to accept the fact that the educational process is necessary to have represented both types of evaluation. A second possible solution is 
to block out formative evaluation as a solution to all the problems associated with the evaluation process, but rather as a step that explains and supports summative evaluation.

\subsection{THE PROCESS, METHODS AND FORMS OF EDUCATIONAL EVALUATION}

In this subchapter methods and forms of educational evaluation in relation to different stages of the evaluation process shall be the subject to presentation of our analysis, as the selection or application of any method depends on at what stage of the evaluation process they are.

Evaluation in schools enjoys great interest on the part of the public concerned, since this area of the teacher's educational activity strongly affects students, their parents and the teachers themselves. Besides, of course, educational evaluation has an impact on the relationship of that the learner to the subject, the teacher, the school, as students will regard the evaluation of teachers as fair.

For evaluation in school practice using a variety of evaluation techniques which teacher deliberately selected (which it has not even substitute, combined with each other) with regard to the learning objectives, target evaluation, situational factors, the students themselves, which is the object of evaluation, not least with taking into account the particular stage of teaching or evaluation process.

In assessing students, teachers use a variety of forms, selected depending on the aim of the objective, evaluation of individual peculiarities of students, and the nature of the situations covered 
by the evaluation. The forms of evaluation are ways in which the teacher informs students about the evaluated results of their work. Nonverbal expressions of appreciation (smile, nod, facial expression, gesture, tactile contact, eye contact, physical proximity to students, and posture) existing individually or as accompaniment to other forms, are either positive or negative evaluation. Paralinguistic aspects of speech, which implement audible verbal expression. It is the speech volume, speech rate, pauses, word emphasis, colour of voice, intonation, rhythm, and/ or acoustic filling breaks (Horvathová- Szököl, 2013, 95). Simple verbal evaluation is based on verbal expression of the teacher's satisfaction (yes, well done, nice, I agree) or dissatisfaction (careful, wrong, no, I do not agree) with student performance. Nonverbal means of evaluation, the use of paralinguistic aspects, and simple, verbal evaluation are applied by the teacher in particular to the content analysis of student performance, that is, in assessing the students' course of the learning process. Thus, the application of interfering intervention is overseen in the internal processes of student learning. These forms of evaluation allow the teacher to implement corrections in student workflows, follow the application of regulative and educational roles of educational evaluation as a means to express the teacher's idea of the student, and so forth. It is therefore necessary to work with forms of evaluation adequate to the situation, the aim of the objective, with close relevance and awareness of the positive and negative impact on the student's personality and learning process.

A typical example of quantitative evaluation is an expression of grades according to the classification scale. Teacher performance evaluation can also be expressed in points, percentages, and calculations of the correct or incorrect results. Other, 
non-traditional forms of evaluation are various symbols, stamps, cards, which are used to express the level of student performance. Public performance appraisals of students are mainly applied if the student has reached extraordinary achievements. Thus, the student (name, photograph) may appear on the class bulletin board, the school honour roll, the school website, and/or the school magazine.

The basic rule of evaluation, regardless of the selected methods and forms, is the application of individual approach, avoiding standard formulation and routine phrases sorting students according to the results into categories without understanding the context. Such evaluation can affect the child's individuality - is losing credibility and is essentially little true. The evaluation should specifically define what a student knows what s/he does not know, what his/her capabilities are and how these skills are utilized. These conditions are mostly fulfilled by verbal evaluation, which is understood as a qualitative evaluation of the performance and behaviour of the student, expressed in the form of a verbal message. In principle it applies to verbal evaluation that should include data on the students' personal achievement, i.e. comparison for example on how s/he worked at the beginning and at the end of the evaluation period, the pursuit of effort, and attitude to learning, about the strengths and weaknesses of their performance with an emphasis on the student's learning process. Well-implemented verbal evaluations contain in addition to evaluating the quality of achievements, analysing the causes of goals and, if necessary, proposals to improve the situation. Among its positive aspects, unquestionably, it focuses on positive support and development of students instead of pushing power, it stresses the importance of cooperation instead of competition, provides 
students an equal chance rather than their elimination, provides individual support instead of the same frontal procedure, allows implementing a content analysis of the learning process. It also allows better traceability of the performance expectations set by the teachers, traceability of the compliance with established evaluation criteria and how these expectations and the student meets these criteria. With verbal evaluation it is not appropriate to use the words of the area of classifications - excellent, very good, good, satisfactory, or unsatisfactory, as not to be confused with grading. The spirit of the evaluation, however, should be stimulating. The starting point should therefore be made of that which is positive for students, what they have mastered the best, since positive evaluation has a more incentive effect than the negative. An important condition is that the teacher should never compare students with each other.

Each evaluation is an expression of a certain quality, or value. But to what extent it considers relevant, accountable and equitable depends on the person to whom, what about, and what these statements of quality denounce. From the standpoint of cybernetics, evaluation always denounces of the aim and the given process in which they occur.

Teacher evaluation, independent of the type that we use, according Golnhofer (2003, 405-408) consists of the following, well-distinguishable stages:

- Setting goals, planning and organizing of educational evaluation

- Gathering information, selection of methods, equipment, tools to assess the phenomenon of educational reality

- Evaluation and interpretation of results

- Deciding on the proposal forecasts. 


\subsubsection{The stage of setting goals, planning and the organization of educational evaluation}

The achievements of educational activities are usually equated with the objectives set. It is therefore essential for the objectives to be set allowing their evaluation and measurability. It is necessary to establish the objectives of the learning subject (in general, those are found in the national curriculum), then proceed to the aims of individual cognitive (effective and psychomotor) field of performance, and expressed mainly in the operationalized form. Operationalization means the expression of an aim in the specific form of the learner's performance, what a student should know and at what level, thus allowing the performance review. This stage of evaluation inevitably includes the planning and organization of the evaluation (Gavora 2010,17). When planning, it is to be decided on who it shall develop and conduct, as well as how to be organized and what conditions must be met. This stage of the evaluation process is remarkable in that its implementation is the exclusive responsibility of the teacher, who takes part in it and is solely created by him/her, the student does not participate in it directly. It is therefore expressed by the activities of the teacher.

\subsubsection{Information gathering stage, the choice of methods, instruments, tools to assess the phenomenon of educational reality}

This stage of the evaluation process has been characterized by an interactive relationship between teachers and students. Teachers 
and students perform in it actively, whose actions mutually interact.

The information gathering stage can be divided into several sub-phases, further formulated by Vališová and Kolář (2009, 181190). The starting point of the stage of collecting information is assigning an exercise. There already are quality evaluations to be experienced at this stage, which are based on how the teacher's role defines what type of job is specified and how difficult the task is. The assignment does not only stipulate the evaluation competence of the teacher, but also the relationship with the student, the expectations from the students and, not least, in relation to the previous stage - setting the evaluation target. In a subsequent, micro stage information gathering, called exposure performance, the student submits the required knowledge, answers particular procedures, and solves problems with the teacher closely monitoring the accuracy of the learner's process. Already here, if necessary, the correction process is carried out. The teacher also often uses some form of evaluation. Non-verbal communication means (stroking, facial expressions, approval or rejection gesture, smile), paralinguistic aspects of speech (voice tone, intonation, colour, etc.), or simple verbal evaluation (right, wrong) agreement or dissatisfaction with the working procedure of the student.

\section{Traditional evaluation methods}

The information gathering stage implies the use of specific methods and forms of evaluation, of course, depending on evaluation objectives. When evaluating the cognitive skills of students, traditionally these methods of evaluation are used: oral answers 
(testing), written responses (testing), where we also included educational tests and practical tests.

As a universal, general and essential evaluation method the method of systematic observation is also considered, as it is ultimately integrated into all the other methods. The systematic observation method is based on the analysis of verbal expressions, the monitoring of changes, recognizing the individual characteristics of each student, the nature of social relations in the classroom, the analysis of student activities (articles, drawings, written work, etc.). It is implemented with adequate forms of educational evaluation.

\section{a) The method of oral replies}

The method of oral replies allows the teacher to monitor and evaluate the students' speech. The teacher indicates his/her position on the students' working methods through evaluation forms (non-verbal, paralinguistic aspects of speech, a simple verbal evaluation). I note this moment mainly because it quite significantly helps in building communication competences of students, which is one of the general objectives of education and training (Szököl-Horváthová 2013, 47). The method of oral testing (oral replies) may have an individual or frontal form (depending on the number of evaluation participants). It can be implemented as a coherent monologic speech of individuals or groups (poem recitation as a whole class) or as a dialogue. If the oral examination is conducted via dialogue, the importance of questioning techniques is emphasized. The questions the teacher asks the students differ in formulation, priority-target, coverage, however as the most important factor we consider in accordance with Gavora $(2010,42)$, are the cognitive complexity 
issues. It means how much thought effort a student is forced to make if he wants to answer the question appropriately. We agree with Kolář and Vališová $(2009,175)$ that high-intensity evaluation can be drawn from Bloom's cognitive domains, when evaluation, or the ability to achieve undertake evaluation premises, to assess situations (in which they take place, and affective components such as experiences, attitudes, beliefs, values of the evaluator) is at the highest levels of hierarchy of cognitive objectives (Albert 2012). Oral tests (reciprocation) identify and provide information on the acquisition of facts, event structures, the ability to create context, comparing phenomena, finding similarities or differences. At the same time they inform of the precision and accuracy of expression, formulating ideas offer an image and the ability to speak publicly.

Currently, testing students orally dominates in our schools, especially testing the individual at the board.

The advantages of oral testing:

- Oral testing is more personal, more human than a written test,

- The personal characteristics of students can be evaluated simultaneously.

- It is more flexible than a written test,

- The student tested can defend the thesis/opinion, expand and illuminate the answer.

- The teacher can see the in-depth knowledge of the student, analyse the learning process and progress.

- Students may learn via oral examinations to supplement the missing gaps in their knowledge.

Shortcomings of oral tests lie in the fact that: 
- The personal contact while oral testing raises the subjectivity of the evaluation (causing it especially by the so called "halo effect", i.e. the first impression, appearance of the student, his/ her behaviour, temperament and so on).

- Each student receives different tasks, so their answers are difficult to compare,

- The exercises do not cover representatively the whole curriculum (no observed validity)

- A lot depends on the teacher's mood,

- Students are affected by stage fright, fear, etc.,

- Moreover, individual testing results in substantial loss of time (individual testing two to three students at the board often takes up to $40 \%$ or more lesson time and the remaining e.g. 30 students do not do almost anything).

Due to these weaknesses in most economically developed countries in the world, the oral test as the classification of students is disused. More objective and rational means of educational control are sought, such as the educational tests.

We offer several options to streamline oral tests in the conditions of our schools.

- The prerequisite of objective evaluation and classification is the knowledge of a student's personality, i.e. diagnosis (information from class teachers, student observation, study products of student activities, educational documentation, interviews with parents etc.).

- The tasks and names of students tested must be part of the preparation for teaching.

- Questions should cover the most important parts of the curriculum (basic curriculum) and should be focused on a number of levels 
of learning, not only to remember but also to understand and transfer.

- Students should be tested not only the latest curriculum, but the basic curriculum as well (students, however, need to know which is the core curriculum and that it will be tested throughout the school year).

- During individual testing it is necessary to ensure a full operability of other classes of students.

- Tasks need to be clear and understandable.

- A student is to be evaluated and classified aloud, in front of the whole class (so that students have an opportunity to get to know the teacher's demands and criteria).

- If the student receives a bad grade, it is necessary to give him/her a chance to correct it, especially enable the weaker students, and to voluntarily sign up to reciprocate.

- Permanently realizing frontal testing, in particular to achieve regularity and a consistent studying of students (classification can be achieved with this method, for example, if the correct answer is a good point, the wrong one is a bad point. A certain number of correct answers represents a good mark and vice versa, the wrong answers represent an insufficient grade).

- Preferably, the teacher can pre-identify 3-4 students, who are called forth more frequently during the entire teaching unit and at its end, and they are evaluated and graded.

- The final grade (level of classification) is not determined based on the average marks for six months. Grades of individual and frontal testing, graphic works, classification protocols, and final and progressive educational tests have different importance, which depends on the objectives and subject curriculum. Major importance should be given the marks obtained from 
the reciprocation of students covering the largest part of the curriculum.

\section{b) Written tests}

Written tests detect and provide information on the quality of knowledge and skills, the level of understanding of the curriculum, the degree of the student's independent thinking, the ability to concentrate, and the skills to organize their thoughtprocess. It also provides a picture of creativity, consistency and accuracy of the student. The rating is usually in percentages, and these are accompanied by a written comment. Gavora (2010, $51)$ in this respect allocates an extra method of written works under free, coherent, and longer works and methods of didactic tests. Gavora (ibid) believes that free written work tends to focus on higher levels of cognitive processes of students, whereas educational tests and knowledge and skill tests usually tend to focus on lower levels of cognitive processes (although this is obviously not a rule). Evaluation by methods of written works is advantageous for students because it allows them to proceed at their own pace and in addition, students are not exposed to the stress of public speech. This evaluation is time consuming for teacher, as each paper has to be read several times, the advantage is however, being able to return to any of them at any time and make an overall picture of the performance of the whole group, and calmly rethink or reconsider any judgement. Therefore, in comparison with oral testing, it is more objective. Forms of evaluations are limited with this method, because the teacher is not in direct, close contact with the student and it is not possible to carry out immediate feedback. 


\section{Alternative evaluation methods}

Students experience the atmosphere of teaching as primarily positive or negative depending on how the teacher evaluates.

In traditional evaluation it is assessed according to a uniform set standards (NR - norm-referenced rating), which represents classification schedules and determines the content of the curriculum. This leads to an evaluation of performance according to standards (to evaluate relative performance), students with weaker evaluation of what a student does or does not know. One student's performance is compared with the performance of other students. This form of evaluation creates a group of the best students and groups of good and poor students in the classroom, as well as so called slobs. In classes where NR evaluation is used, the students compete among themselves. If a student is transferred to another class where there are different students, while addressing an exercise, a same didactic test for instance, his score would be completely different from the original (relative performance). NR evaluation is used mostly in the traditional classroom, in the school admission procedure, in cases where the students, teachers and schools need to be differentiated.

Classification by marks has become the main form of evaluation at schools and for school and the key measurement of the student's success for schools and parental audiences alike. Such an evaluation, coupled with strict control and frequent testing, evokes negative mental states which block the development of the child.

Efforts to objectify evaluation through standards leads to less responsibility for student evaluation, the reliance on the state standards and that teachers have little awareness of their personal evaluation. 
Teachers create their own evaluation standards from their idea of a successful student. This comparison of successful trainees may not be fully conscious. They are significantly affected by preferential attitudes of teachers, such as talent preference, diligence, students' personality traits but also their own fondness, and so forth.

Teacher's evaluation also influences subjective errors, which can also be unconscious, for example prejudice, inability of empathy, influence of one's nature, the teacher's mood etc.

Everything ungraded, teachers, students and parents alike perceive as less important, and it weakens preference and skill attitudes in education. This implies the need to seek recourse in another sense of evaluation.

Petlák $(1997,223)$ allocate, in the context of growing concern for the development of alternative means of surveys of knowledge, alternative methods of student evaluation - learning agreements, authentic evaluation, portfolio evaluation to which Šikulová and Kolár $(2009,34)$ advise peer review and independent evaluation. The given method offers a more detailed view on portfolio evaluation and an independent evaluation due to them being a basis for evaluation humanization needs in the school.

The issue of student evaluation in connection with the efforts to humanize education in recent years has brought some inspiring views and direct ideas on how to be read and implement in the evaluation process in school practice in order to assist the actual development of student personality. In this regard, there have also been many new concepts that reflect the change in general perception of function, form and means of evaluation. An interesting example is the idea of learning agreements. The essence of this method is an agreement signed by the students and the teachers, the student 
on the basis of the criteria known in advance, including rules and conditions, undertakes to deliver the final product (a final thesis, term paper, or project) by the agreed deadline in order to get a pre-arranged evaluation. The teacher creates divergent learning conditions for students, and the students decide which option is taken up, thus bestowed upon a greater share of responsibilities in order to affect their results. Some teachers create such a supportive atmosphere, which enables the evaluation of one student's performance by other students (what we call peer evaluation). A great importance in peer review lies in the fact that in this way students learn to evaluate the work results of others, but also themselves in comparison with others, on the basis of already known and cleared criteria. They learn to express themselves, to analyse the situation, compare and evaluate critically.

The concept of authentic evaluation appears, as a counterweight to the traditional knowledge examination. It represents the desire for knowing authentic, genuine student personality. Attention is focused on the evaluation tasks important for practical life (the ability to produce something - models, charts, log books, records, projects - or act). One of the forms of authentic evaluation, and which may even exceed its framework is the portfolio.

\section{a) Portfolio evaluation}

Some domestic and foreign professional studies, especially those that are based on some measure of giftedness and talent (e.g. fine art, art, journalism, doctorate studies) traditionally require prospective students as early as the interview stage to present an illustrative selection of their own work. Similarly, in taking up certain professional occupations a competitive set of personal education 
records, letters of recommendation, samples of their own work and other supporting documents of applicants are required from junior absolvents (but often from seniors as well). They document their past experience, actual skills, potential abilities and personality tendencies and unique samples of their school curriculum vitae may be necessary as well.

In terms of the first grade of primary schools for several years the possibility of verbal evaluation has existed, which also opens the way for the use of the portfolio. Attempted systematic and comprehensive guidance in the education of students of younger school age is also posed in the Alternative Methods Manual - Step by Step (or.: Alternatívna metodická príručka - Krok za krokom) (2000) approved by the Ministry of Education. It is the result of four years of experimental testing within the project of Wide Open School (Škola dokorán) (Šimčáková-Končoková 2000 Šimčáková Končoková-2001) in terms of the first grade of primary schools. The mentioned methodological guide understands portfolio as a dossier of students' works, which takes the form of filing cabinets, files and folders or boxes, stored in a classroom on site accessible to students. Based on the purpose, criteria and objectives of its creation and use it can include the following items:

- The result of the creative work of students,

- Materials documenting the learning process,

- Self-evaluation sheets for students

- Reflective diary of students

- Authentic records of the teacher's observation

- The teacher's observation sheets

- Records of teacher - student meetings,

- Contacts and notes of the students' parents. 
The portfolio can contain various educational tests, examinations and dictations, which, while not being the preferred techniques of authentic evaluation, still have their explanatory power and therefore cannot be eliminated from school practice.

The results of students' creative work. They are the products of their work in the learning process. In their portfolio they are selected by students, teachers, or get there on the proposal of parents, based on defined objectives and criteria. As a rule, they are results that demonstrate the highest level of achievement of an individual in acquiring the content of the curriculum, and the acquisition of certain skills.

Materials documenting the learning process. They are different concepts, sketches, notes and records, unfinished works, or even pictures showing process as individuals solve project tasks within a group. The function of these materials is to document the nature of the process that led to the acquisition of specific curricular content, skills and abilities. The documentation of the process allows for a better understanding of non-cognitive factors affecting the quality and level of these results.

Self-evaluation sheets for students. Self-evaluation as a complex of relationships with themselves is an important part of the overall self-concept of a student. Self-evaluation competences as a source of self-regulation are perceived as one of the objectives of the process of developing a student's personality. Self-evaluation sheets are a means to provide students with an example of positive standards and criteria by which they can judge themselves. The content of selfevaluation sheets is usually a set of questions that are either bound to any particular activity or target their certain personal qualities. The questions mentor students on the one hand to assess the current level 
of some of their qualities and on the other hand, are an incentive for setting the objectives for the future. For example: Which skills have I improved since last year? What can I do really well? What do I wish to improve this year? What would I like to learn? (ŠimčákováKončoková 2000; Šimčáková-Končoková 2001)

Students' reflective diaries. The teacher leads students to conduct their reflective diaries at an age-appropriate level. They are sporadically or regularly kept records of how students evaluate the course teaching you about important events in their school and family life, their beliefs and attitudes to the problems and issues that arise in their environment, and so on. They may also include comments and opinions about reading books or magazine articles. Diaries are a means of developing self-evaluation and evaluation competences of students and also a means of getting to know their authentic personality by the teacher.

Authentic records of the teacher observing a student. They are records of observing students in various activities and different situations. Through these statements the teacher captures authentic acts of the students, their reactions in certain situations and attitudes demonstrated below. Each record contains a time stamp, or even a description of the situation in which it was made. A series of records for a certain period of time further enhance its authentic image of the student and allows the teacher to draw conclusions about the level reached.

Teacher observation grids. These are teachers' records concluding the actual level of acquisition of one of the students' specific abilities. For example, on the level of graphic expression, reading skills, oral expression, active listening skills, the level of development of psychomotor skills and so on. 
Records of teacher-student meetings. Their aim is to analyse the students' work and solve problems encountered in the learning process, set individual tasks for the coming period to guide their further development.

References and notes from the students' parents. Parents are seen as an equal partner of the teacher and the school. Therefore, among them an intensive two-way communication takes place. Within this, parents have the opportunity to express their thoughts on home preparation of students, commenting on the work that the student chose to include in the portfolio, or provide some characteristics of their child (usually a questionnaire as a result of teacher request).

In general, we can talk about several types of portfolios depending on their content and purpose. Batzle (1992) lists the following types:

- Work portfolio;

- Sample portfolio;

- Evaluation records portfolio.

The work portfolio is a comprehensive dossier that provides a holistic picture of a student's personality. It includes materials documenting the learning process and its outcome. The included documents are the result of the selection of the student, teacher or parent. The work portfolio is the richest source of knowledge and evaluation of progress, reached by the student in the learning process daily.

The sample portfolio is a collection of the best works of the students over time, which is created on the basis of their choice. This may be a powerful incentive for achieving the best personal results for a student, but on the other hand, does not provide for a sufficiently comprehensive picture of the student for an authentic 
evaluation. It plays a positive role especially in the presentation of the results for the parents.

Evaluation records portfolio is usually created by the teacher in whose class a sample portfolio is used. While the sample portfolio is the result of the students' work alone, in the portfolio evaluation there are observation records notes, questionnaires and individual samples of students' work, which did not make it into the sample portfolio and were collected by the teacher, since they may amplify and clarify the overall picture of the results reached by the student, and the nature of the process that led to them.

The combination of the sample portfolio and evaluation records portfolio provide richness, complexity and transparency of sources mainly used for authentic evaluation. The advantage of work portfolio is that it is produced in direct, daily interaction with the student and the teacher with the possibility of an active input from parents in this process. This provides a higher level of complexity and authenticity.

One of the other possibilities how to approach creating of a portfolio is primarily the construction of an assortment portfolio into which all student work and other relevant documents and materials are automatically included. After a certain period of time students and teachers make a selection of materials based on previously agreed criteria, forming a commonly selected portfolio that is structured logically and chronologically and can continue to work with it.

Teachers have a choice of different types of portfolios, or their combinations according to the specific terms of the objectives and options. The basic criterion for a good portfolio is to:

- Be rich in information that enables the most objective evaluation of the relationship between the specific results or performance 
of students and their ability or preconditions for their further development potential;

- Contain sufficient results of student activities and materials documenting the work process, due to which you may recognize the strengths of the students' personality and set development goals;

- Document and also allow the development of effective selfevaluation strategies as a form of individual student evaluation, which is one of the prerequisites for self-regulation and selfdevelopment.

The most frequent use of the portfolio is at consultation meetings of teachers, parents, and students. They are always held in certain periods of time, at least twice in the school year. The teacher with the parents and with the presence of a student goes through the portfolio analysis of individual pieces collected for that time period. In the debate to confront their opinions, students and parents get to know the evaluation criteria and the quality of their implementation by the learner better and they set out together to achieve other objectives in improving the quality of his/her work. These meetings are one of the preconditions of the teacher's individual approach towards the evaluated student. It also provides space for parents as equal partners of the school to know the particularities and strengths of their child in the learning process. They are given opportunities to influence this process along the lines of their own orientation of values and are a means of sharing the responsibility for the students' school performance and overall personal development. The student is an active participant of these meetings. This not only enhances the authenticity of the evaluation process from the perspective of 
the teachers and parents, but it is also a means for developing the students' meta-cognitive functions and self-evaluation competences.

Teacher - student consultations are held occasionally, usually at the initiative of the teacher. Their aim is to tackle the actual problem that has occurred in the context of the general adoption of any particular skill, ability or expertise at any particular curriculum by the student. In this case, they only select those fragments of the portfolio that are relevant to the issue, and through which they are able to uncover the causes, severity, and also the conducts of further development. Current trends of educational evaluation prefer especially those concepts of the portfolio, which focus on the comparison of performance, or behaviour of individuals with their own individual norms, thus with themselves.

In Slovakia, the experience of this new technique of "authentic evaluation" of personal qualities of students is still not spread on a massive scale. However, in many schools they lead - more or less systematically - a collection of samples of student work. Creative teachers, however, apply it spontaneously, in their own individual way. An open question remains: the problem of access to holistic interpretation of such diverse collection of materials and the issue procedures for overall evaluation of educational performance and personal growth.

\section{b) Autonomous evaluation (self-evaluation)}

Autonomous evaluation is an evaluation in which the students evaluate themselves and it can be understood as a separate method, or as part of their peer evaluation, for example. A pre-requisite of autonomous evaluation is the teacher's sensitive and systematic preparation for this activity, which has a deep foundation in the 
formal evaluation through which students learn to evaluate their own work. This means that evaluation by teachers is gradually exchanged for self-learning. This is the most important thing a student can gain from the evaluation process for their own lives.

The relationship between teachers and students is built on mutual trust and respect, to examine individual students in detail and not least, on their involvement in the evaluation process, thereby producing the seeds of the learner's self-esteem. It is a further requirement on the path of humanizing our schools. Traditional schools, however, have not developed self-evaluation, rather replaced it with evaluation authorities - teachers.

In general, by self-evaluation we mean every individual being assessed by him/herself. In the process of self-evaluation it is also possible to distinguish certain stages from its foundation.

In the early stage (start of school attendance) students are entirely dependent on the teacher, when it comes to evaluation, not realizing the importance of learning for life, and is not satisfied by feeling his/her own self-improvement. Recognising the efforts put in to solve a task, and seeing the result of their work, they feel the need of valuation by someone older. The only "criterion" is a teacher's evaluation, by which $\mathrm{s} / \mathrm{he}$ is provided with feedback information, thus orienting the student in further learning. In this period the student's trust in the teacher's evaluation is crucial. If a student internally identifies with it, the seed of self-evaluation is planted.

The next stage is the gradual creation of conditions to form of a student's ability to evaluate. The role of the teacher is to guide this process and expose the student's clear and understandable evaluation criteria. Students get themselves involved in evaluating their classmates, themselves, or even a teacher. Based on 
positive-critical attitudes the common opinion is shaped in a class. Self-evaluation, in the strict sense, starts if operating as an internal (reflexive) evaluation if the students on its basis have the ability to regulate their training and educational activities. The indicated stages are not separated by strict boundaries, they are very closely related, influence each other and overlap.

The basic starting point of the humanistic concept of evaluation is in its orientation on student progress in developing the attitudes, skills and knowledge from the previous state. It is therefore a comparison of the student with himself at a previous time and not with other students or with a fixed standard. Such an evaluation is called CR evaluation (criterion-referenced). In comparison with the standard (NR evaluation) it is only secondary and is carried out at key stages of student development through normative tests, the content of which is based on a uniform set of standards (such an evaluation could be done e.g. at the end of $1^{\text {st }}$ or $2^{\text {nd }}$ grade of elementary schools, before choosing professional orientation after the second year of secondary vocational schools, at the end of secondary vocational schools studies, etc.). In classes where CR evaluation is used, students compete with their school work (not with each other). Teachers identify the elements of the curriculum, which can be acquired by all students (a so called criterion or standard). The aim of the teacher is then to identify (by testing, educational tests, etc.), whether the students have achieved the required standard or not. The teacher is not interested in how much a student has outdone the desired criterion or any other student. Students are therefore not divided into excellent, very good, good etc. categories, but only to those who met the criteria and to those who did not. Unlike NR evaluation, if the student is transferred to another class while being addressed for example the same didactic 
test as in the original class, and even with the same result, the evaluation would be the same (absolute performance).

Kosová (1996) explains that the basis for CR-evaluation should be the following principles:

1. Individual approach in evaluation - is to evaluate the performance of students according to their abilities and capabilities, i.e. the ratio between the performance and ability of the students. Student activity must be evaluated in the light of what steps they took and the allocation of their potentiality. This implies not to take into account the sole result the students achieved, but also the way they needed to achieve it, the magnitude of the effort to outdo themselves.

2. The complexity of evaluation - lies in its focus on the holistic development of the student's personality, not only the knowledge but also the skills and attitudes, not only on the cognitive aspects of a student but also the emotional, social, or moral ones, not only on the amount of stored knowledge, but also the ability to obtain them and work with them, not only intellectual ability, but also manual skills, not only discipline and obedience, but also creativity and independence. It means not to appreciate only intellectually gifted students, the speed and breadth of curriculum acquisition before any depths or relationship to them.

3. Positive orientation evaluation - is based on the idea of humanistic education, according to which the school's role is to ensure that every child is successful. Anyone can be successful in anything. Therefore, the teacher should build on the strengths and advantages of the student, evaluate what a student knows, firstly praise success, then evaluate the negative results, but with an encouraging attitude and expressions of confidence. 
Expectation of success, or at least hope for a positive evaluation is one of the conditions of interest and motivation to work.

The teacher has to evaluate positively and appreciate what s/ he wants to educate with the students, thus e.g. creativity and originality, independence, ability to collaborate, their own opinions and so forth. Meanwhile, positive focus on evaluation cannot be understood as false, deliberately distorted, but as the ability of the teacher to find what $\mathrm{s} / \mathrm{he}$ can be proud of, encouraging and giving students the opportunity to experience the joy of success.

4. The tendency to self-evaluation - has an essential for the development of self-regulation. Therefore, the teacher has to give as much scope for students to evaluate other students, but also to evaluate themselves. Self-evaluation activities cannot be understood solely as the verbal evaluation of their own answers or the use of worksheets for self-testing. It also means to re-use self-evaluation and reflecting on their own work after certain curricular areas or time periods for example through selfevaluation sheets to complex oral or written evaluation as to achieve personal progress after about six months.

5. The openness of evaluation - means the possibility of changing evaluation after conditions change during the learning process. This is both to ensure that the teacher does not evaluate students emphatically, respectively not to select specific students, not to evaluate them as something fixed, but to consider them as something potentially changing. On the other hand, it is necessary to conduct a critical review if a student can handle the whole curriculum with regard to their personal pace. If, for example a student meets the content, which was necessary to adopt according to the curriculum in February and in April, is 
to be evaluated by the curriculum mastered. Faced with graded classification, however, in that time the student accumulates several bad grades, which limits the ability to change this negative evaluation.

The most important diagnostic methods include analysis of performance and student work. The joint analysis of their work (entering, drawings, etc.) gives the learner enough feedback to make the necessary corrections.

\subsubsection{The stage of evaluating and interpreting results}

Even at this stage, at least two sequences can be recognized - partial phase stages. The first of these, in the final analysis of performance, the teacher has to carry out, in a relatively short period of time, a vastly consuming analysis of student performance. At this stage, the overall student performance is evaluated. The teacher should approach this activity with maximum responsibility, while being aware that the evaluation is formative for students (which means that depending on the attitude of the teacher towards the evaluated student is forming his character towards further study, or himself) and also opinionforming for teachers (meaning that based on what position the teacher takes regarding evaluation and the student, the other students in the class will share the opinion). It is therefore quite natural for the teacher evaluation to also involve other students (thus the teacher applies the method of peer review). That's not used as an alibi, but in order to have his/her ideas established in his, or the other way round, perhaps the views of the students in the class made him re-evaluate his/her initial decision. Here 
the teacher can give the students space to express themselves, therefore applying the method of autonomous evaluation.

The second micro segment of this phase speaks of expressing an evaluation decision. The decision is made by comparing the current status of the evaluated students with their past status and the state required by the criteria (Gavora 2010, 19). The teacher uses the standard specified by the educational program as the main criterion. The verdict may be communicated towards the students in almost any form of evaluation. This is mostly done in the form of quantitative evaluation, specifically classification, simply by a grade. It can be enriched by verbal comments, simply the teacher's reasoning. This is also associated with non-verbal expressions of the teacher that the student perceives intensely and multiply the final result (effect) of the evaluation. One of the most effective forms of educational evaluation is verbal evaluation to which I hereafter devote more space.

\section{Verbal evaluation}

Classification expressed through grades has been a proved and extensively executed evaluation in our schools. It is not possible to talk about the complete absence of the word evaluation, since it existed - at least theoretically - as a side feature of classification in the form of verbal reasoning of grades, praise, encouragement or negative verbal expression. When looking for the advantages of classification it has been emphasized that this is a "traditional way of evaluating students, which has buried itself deeply in our thoughts and has become a classic. It satisfies practical needs. Mathematical expressions of benefit corresponding to modern requirements of time (possibility of the automated processing of results). 
A serious problem is the lack of clear criteria for grades in classification, but on the other hand, grades are an important criterion for evaluating the success of students (teachers, schools), although apparently they do not correlate with success in life.

Grades often tempt to "non-teaching accounting", i.e. averaging, rounding, and "percentomania" when the teacher's personality disappears and hides behind the almighty grade.

While the teaching process is dynamic, the grade is undoubtedly static. In relation to students a great lack of classification is in particular that it does not express the individual differences between them, it is not possible to see the differences of dependency among the influencing factors.

Grades also affect the social atmosphere in the classroom. They enact social inequalities between students; in addition, many of them see them as a source of fear, stress, tension, injustice and resistance to learning. This is proved by a "prominent" place in child neuroticism, as well as a relatively high number of child suicides, many of them happening due to grades.

An argument against classification is the fact that grades had been promoted to the main learning objective. The real learning objectives become secondary and all efforts were directed towards students 'exchange' of knowledge for good grades, which continues to exist in many families as their benefits were "sold" parents. Focusing on grades has become one of the main causes for the loss of the original denotation of teaching - orientated towards the development of knowledge.

Verbal evaluation may be characterized as "quite specific - describing the evaluation based on the content of teaching, indicating the mastering of educational objectives. Verbal evaluation thus does not only evaluate the work of the student, its 
task is to show how (and why) certain results have (or have not) been achieved.

Verbal evaluation should take into account that the cognitive abilities of students (e.g. understanding, observing, memorizing, language expressions, reproductive and creative thinking, etc.), as well as their attitudes towards work in general and especially school work, interests, individual and social behaviour. It should also take into account the physical and medical characteristics of students (unless they influence their success at school in some way), as well as the peculiarities of the school, for example tougher conditions, shifts, and so forth.

\section{The basic features of verbal evaluation}

1. Verbal evaluation should specifically label what the students know and what they do not know, what their abilities are and how to use them. This verbal score becomes much more consistent than the harsh classification. The teacher, applying an individual approach to students to separately evaluate their work, praises them for their good performance, tells them where they were wrong, and advises on how it can be corrected. An important requirement is to evaluate student performance immediately, with a minimum interval, because it is the time when the effect has the highest rating.

2. The overall spirit of evaluation should always be encouraging. The teacher should begin evaluation with what the student has mastered the best, for which knowledge s/he can be proud of. Not only what the student knows well, but also what they did for improvement and for their self-development should be appreciated. After that can the teacher mention what the student mishandled, and this "criticism" should be followed by an optimistic outlook to the 
future. This approach is consistent with the humanistic approach, with the so called rejection acceptance technique.

3. With verbal ratings the so called social relation standards must be avoided, where the performance of an individual student is compared to the performance of other students in the class.

4. Evaluation should always include a comparison of where the student stood at the beginning of the year and the progress $\mathrm{s} / \mathrm{he}$ performed during the period. This is a recording of a student's performance and the use of the individual relational standards where teacher "evaluates the performance of individual students compared with their performance history, i.e. breakthrough times in intra-individual development.

As to the actual 'act' of evaluation, it is not appropriate in our opinion, if the first person who evaluates (mainly the verbal performance of students) is a teacher, and students can only (dis) agree with the statement of evaluation, respectively repeat it or give their approval or disapproval of it. They will be much more attentive to the statements of their classmates (and their own) if they know that they will be evaluating (they will be evaluated by their peers). A big contributing part is the fact that the teacher is a great authority in the eyes of a student, who s/he does not want to contradict. Therefore, we believe it is more appropriate if the student is initially rated by peers. Then the evaluated student should be able to express his/her own opinions to make room for a possible controversy and ultimately the students' discourse would be reviewed by the teacher. S/he would, as appropriate, correct any mistakes that were committed in the students' evaluation or repeat the agreed evaluation criteria. We consider the student's written opinion as the appropriate form of self-evaluation. 


\subsubsection{The decision phase of the prediction draft}

At this stage, one can distinguish three sub-phases. The first is to say specific recommendations on how to respond to the outcome of the evaluation, how to make corrections and how to use the potential of the evaluated student. The teacher may also propose the implementation of specific educational measures, in which not only s/he participates, but also the evaluated student, or even the whole class. With good reviews, preconditions for further development of the student are similarly expressed, with which another sub-phase of the final stage of evaluation has been suggested. Expressing the prognoses reveals the students' options and the ways of their further improvement (Gavora 2010, 19).

This phase is finalized, as understood by Kolář and Vališová $(2009,187)$, by the sub-phase of the awareness of the potential impacts of evaluation on students. It is performed solely by the teacher, and takes place in the form of intra-communication (asking questions, replying to them, search for reasons, argumentation, etc.). For the teacher, estimating what the students' evaluation caused to the students, where it moved them, must be preceded by a perfect knowledge of their students.

\subsection{THE RULES AND CRITERIA OF EDUCATIONAL EVALUATION}

In order to evaluate effectively, to fulfil its functions and, ultimately, to be a means of shaping the students' personality, it is necessary to stress another important aspect which can also help increase the objectivity of the evaluation, thereby determining the presence 
of clear pre-agreed rules of evaluation. Those familiarize students with specific values and the expected results, which correspond to the appropriate grade or verbal evaluation (Valent 2008). The rules should be clear to students, logical and pre-determined. Rules for the valuation testify about what the ideas of the teacher are on the final, ending product with which the students demonstrate the level of their knowledge (skills, abilities), and the means of achieving them. Thereby the teacher gives students a clear overview of what the subject of evaluation (objective evaluation) will be, at what intervals the evaluation is implemented, define the methods and forms of evaluation, sets deadlines and diversifies options to achieve the set goal. This way students with different cognitive preconditions have the possibility of achieving a positive evaluation and thus, experience success. Evaluation can therefore fulfil all of its positively perceived features - in addition to the traditional understanding of informative, also widens it with motivational, regulatory and particularly educational functions, as it understands students as active learning entities, who learn to take responsibility for the results of their actions by evaluation. In determining the rules for evaluation, the teachers are recommended to:

- evaluate verbal and written (graphic) expressions under clear criteria which are known in advance to students,

- choose optimal methods of managing the curriculum and specific forms for students for examining

- evaluate the performance of students in order to have a positive and motivating character,

- use continuous formative (informal) evaluation to motivate students' progress, 
- apply summative (formal) classification evaluation once acquiring and consolidating the thematic whole or related subject themes,

- encourage children to (self)evaluate their performance and the progress in learning,

- through continuous and final feedback detect the understanding of the curriculum, reaching the objective in question and the level of mastery of basic knowledge of the subject topic.

The basic criterion for evaluation at school and in the classroom is the stated objective. The objectives are stated in school educational programs formulated as key competencies of students turning into reality in the form of the graduate' profile. The graduate's profile therefore represents "a synthesis of achieved qualities and formulated core competencies" (Kolar-Šikulová 2009, 122). The teacher decides which key competencies will comprise (a process) to develop teaching. Thus, it is for him to spread the competence of the particular knowledge, skills, attitudes, from which consist of competence. This means that the teacher defines what a student has to know (content knowledge, skills) and at what level (extent and quality of knowledge, skills) to be in possession of a given competency. The stated objective determines the content of teaching, selection of appropriate teaching methods, strategies and policies, and therefore the selection of appropriate methods and forms of evaluation. To sum up, it can be stated that while setting up a system of control and evaluation of students' learning outcomes:

1. The evaluation is made on the basis of certain criteria that can be (Szököl - Horvathová, 2013, 243) quantitative (related to the learning process at a lower level - remembering, application, e.g. the student gets at least 7 correct answers out of 10) and/or qualitative (associated with more complex learning processes 
- synthesis, evaluation, creativity) to be used for monitoring student development;

2. These criteria are precisely defined and determined, as well as

3. The criteria for disclosure.

\subsection{THE MICRO LEVEL OF EDUCATIONAL EVALUATION - THE STATE OF RESEARCHED PROBLEMS}

In this unit I am going to analyse evaluation at a school's micro level. Therefore, I only introduce an illustrative insight into how teachers perceive and appreciate evaluation questions in the classroom in practice. I took the results of empirical research published in domestic and foreign literature as a starting point in drafting this section. I conceived them to emphasize their multidimensional nature as well as documenting the views of individual researchers on the issue under consideration. At the micro level, the subjects of evaluation include the process and outcomes of education and training, in terms of the students themselves or the class, which are implemented mostly by the teacher.

The research results highlighting a cybernetic view of evaluation in the priority of feedback in educational process management (Uhereková 2009, 13) suggest that feedback as a control function to establish compliance with the educational objectives is used continuously in making the curriculum by less than half of the teachers of the research sample (579 Science teachers at primary schools and secondary grammar schools in the SR), at the end of the lesson it is applied by only a third of them. More than half of the teachers checked the level of knowledge mastery when 
completing a thematic unit or related subject topics, nearly a fifth of the teachers did no control at all.

The importance of feedback in the classroom, but specifically for evaluating writing skills in the subject of English is the focus of research for Sršníková (2011). The priority objective of the research was to find out basic information about providing feedback and evaluation of writing skills in English, the most common methods used for error alerts being the extent to which students are aware of the evaluation criteria used by teachers of English in evaluating their essays. The survey, which was attended by 134 respondents, 83 were students $(62 \%)$ of advanced level and $51(38 \%)$ students were beginners, shows that the skill of writing is the least exercised skill within the lessons of English, because the respondents' answers revealed that $59 \%$ of beginners and $75 \%$ of advanced students had written an essay in English only once every six months. All students reported that evaluating the skill of writing in English is provided to them in the form of a final mark. None of them mentioned his/her writing skills being evaluated verbally, by points or a combination of grades and verbal / written comments. $24 \%$ of beginners and $42 \%$ of advanced students know the evaluation criteria of writing well. $69 \%$ of beginners and $51 \%$ of advanced students know the criteria in part, and in both groups $7 \%$ of students claim that they do not know the evaluation criteria of writing in general.

Mapping the applied traditional forms of teaching evaluation by teachers in the classroom is dealt with in a number of researchers. Krelová (2005) examined the views of 30 teachers of vocational subjects with the method of questionnaires in secondary technical schools. Research has shown that teachers prefer the written examination which they consider more objective than oral tests. While $56.7 \%$ of teachers said that grades along with verbal evaluation 
is considered the most correct and almost $50 \%$ of respondents found the motivational function of evaluation the most important. Dytrtová and Krhutová (2009) conducted a research of 54 teachers of technical education subjects in the lower secondary levels, which was aimed at finding the most widely used methods of teaching evaluation and their forms. The research results show that $27.78 \%$ of teachers try to evaluate collectively. $24.07 \%$ of teachers always apply oral tests, $16.67 \%$ of teachers try to evaluate individually at all times. Despite the importance of continuous testing, only $11.11 \%$ of teachers always try to test continuously. Teachers often test in practice $(55.56 \%)$, continuously $(51.85 \%)$, en bloc (49.06\%) and orally $(42.59 \%)$. Sometimes teachers test in groups $44.44 \%$ and $39.62 \%$ of teachers test en bloc. $37.04 \%$ of teachers rarely test in groups and $25.93 \%$ of teachers individually. $11.11 \%$ do not test in written forms, and $9.26 \%$ of teachers do not test in groups.

The teachers' orientation in alternative methods and forms of evaluation was examined by Veselovská (2010). Specifically, the research aimed to find out whether teachers use praise, portfolios, questionnaires, self-evaluation, and evaluation-communication groups. The views of teachers and students for their application by teachers were compared. The research sample consisted of 44 teachers and 142 secondary school and secondary medical school students. Most respondents said that technology and nontraditional forms of evaluation (portfolio, communication groups, self-evaluation, questionnaires, ..) designed to develop the selfesteem of students in secondary schools are not used at all or are applied by very few teachers. The opinions of teachers and students in this area did not differ. $30 \%$ of teachers along with students concurred that they had never met the portfolio and do not know nor use this form of evaluation. 
Tináková (2007) also investigated the use of alternative methods of evaluation, but from the perspective of the students of the Faculty of Materials Science in Trnava. The survey shows that $57 \%$ of students faced challenges through the portfolio, $29 \%$ of students faced challenges through grading individual work and transferring points for exams, $14 \%$ of students faced challenges through authentic tests of practical knowledge, and $0 \%$ - had experience with other offered non-traditional methods of verification.

As you can see, there are several publications with problem, skill and knowledge evaluation analyses, but only few of them deal with evaluation as well as with other cognitive abilities of students. This gap is filled with the research of Dytrtová and Krhutová (2009), who investigated the extent of the usage of the evaluation criteria of students' psychomotor skills and the personal attitudes of 54 teachers of technical subjects at lower secondary schools. $46.30 \%$ of teachers always evaluate the ability to work independently, $46.30 \%$ evaluate the creative approach to problem solving and the method of applying theory in implementing the tasks at hand is evaluated by $38,89 \%$ of teachers. It is satisfactory that the importance of creativity in the learning process and the students' personality development is appreciated by teachers. $61.11 \%$ of teachers evaluate the accuracy in activities, $50.00 \%$ evaluate a creative approach to problem solving and $44.44 \%$ of teachers praise occupational safety and hygiene. $40.74 \%$ of teachers sometimes evaluate students' own working mechanisms. The organization of working places $(29.63 \%$ ) is rarely evaluated by teachers just like the overall care for their environment (27.78\%). $18.52 \%$ of teachers never evaluate the compliance with the time needed to implement the anticipated activities. 


\section{SUMMARY}

The fourth chapter, Categories (types of) teaching evaluation is divided into three subsections. In the first one I dealt with the processes, methods and forms of educational evaluation. In the second subchapter I dealt with the rules and criteria of educational evaluation. The third one was dedicated to the micro stages of educational evaluation - the state of research problems.

The types of evaluation can be divided depending on what function of evaluation they perform, at which stage of teaching they are applied and what volume of information they verifies. According to the degree of the sophistication of evaluation information, we distinguish diagnostic, formative and summative evaluation. Diagnostic evaluation shows the current status of the entry-level skills of individual students or groups of students, the results of which help the teacher in the planning and management of teaching throughout the school year. Formative evaluation allows the teacher to make corrections, solve the learning problems of students and use their positive results. In teaching, it especially fulfils educational and motivational functions. Formative evaluation does not preclude classification. I found that formative evaluation focuses on the process of evaluation and the use of feedback monitoring in the development of student competences. Summative evaluation summarizes what the student has learned and what properties have been acquired. It focuses on the product, the result of the student's work. This, however, requires comparing student performance with social standards, criteria and is usually expressed by formal classification. Thus, it often fulfils the function of differential or selective educational evaluation.

According to the extent of exercising the functions of educational evaluation, while applying the horizontal section I 
expressed bipolar kinds of educational evaluation: cognitive and humanistic, holistic and analytical, quantitative and qualitative, negative and positive, and normative and criterial. In applying the vertical section of the defined, bipolar types of evaluation, the characteristics of summative evaluation crystallized (in terms of cognitive, analytical, quantitative, normative and negative reviews) and formative evaluation (in terms of humanistic, holistic, qualitative, positive, criteria-based evaluation).

In subsection 4.1, The process, methods and forms of educational evaluation I introduced the teaching methods and forms of evaluation in relation to different stages of the evaluation process. This aim is reflected in structuring the subsections that I have in terms of stages of educational evaluation composed of four stages: the stage of setting targets, planning and organizing the educational evaluation phase of information gathering, selection of methods, equipment, tools to evaluate the phenomenon of educational reality, the stage of evaluation and interpretation of results, and the decision phase of the prediction draft. To explain the substance of these stages, I defined the most frequently occurring and specifically applicable methods and forms of educational evaluation.

In order to increase the objectivity of evaluation clear, preagreed rules and evaluation criteria must be set. I dedicated this aspect to the second subchapter of the fourth chapter, highlighting the rules and criteria of educational evaluation.

In the third subchapter, titled The micro level of educational evaluation - the state of research problems, several studies on the evaluation of today's schools were presented together with their results in terms of classes and students, looking at the issue under consideration from various aspects. 


\section{CONCLUSION}

The views on education in different periods of socio-cultural environment development are gradually changing, which is reflected by the demands of society, the various approaches to the status of teachers, children, students, or undergraduates as well as by the different philosophies of the learning process.

Educational evaluation is one of those educational disciplines, which has its general basis and consists of almost every specialized field of education. It provides feedback, monitoring and the evaluation of the educational process.

School education is like any other human activity, evaluated by merit. Unlike human activities that produce results in a material form, learning outcomes remain hidden in the consciousness of the educated population and in society it is usually unapparent until after a long period of time passed after finishing school education courses. Controlling the learning process is a significant act in several respects. In addition to its essentiality for the evaluation and classification of students, the teacher is also given some feedback, which informs him/her about the effectiveness of his/her own work. Teachers may reveal confusion in the minds of students or correct errors of reasoning. On the basis of regular checking, the teacher gets acquainted with students and with their personalities and develops an idea of their possibilities for the future. Evaluation is a powerful means of stimulation and is of great educational importance as long as it is fair and just.

One of the main features of educational evaluation is its close connection with the aims and objectives of education and training, particularly with the object of education and pedagogy. It also studies the impact of several factors and conditions on education. 
Content aspects are based on the curriculum of the requirements for the ethical, professional, aesthetic and physical development of a student.

In the 21 st century a knowledge-based, learning society has become an even more important priority. The primary task of the teacher is to create a well-functioning class team in which students successfully achieve goals and meet requirements. All of this requires high quality educational activities from the teacher. S/he must be able to organize, plan, work with students, respect them, solve problems, think critically, be creative and flexible etc. and above all be accountable to their students. 


\section{REFERENCES}

ALBERT, S. 2012. Špecifické ciele a didaktické testy. Komárno: Inštitút celoživotného vzdelávania. 62 s. ISBN 978-80-970308-5-8. ALEXOVIČOVÁ, T. 2007. Alternatívne školstvo v kocke - 1. čast'. Prešov : MPC. 37 s. ISBN 80-8045-438-8. [online]. http://www. mcpo.sk/downloads/Publikacie/Ostatne/OSALT200801.pdf. [cit. 2015-10-10]

BATZLE, J. 1992. Portfolio Assesment and Evaluation: Developing and Using Portfolios in the Classroom. Cypress, CA: Creative Teaching Press.

BÁRDOS, J. 2002. Az idegen nyelvi mérés és értékelés elmélete és gyakorlata. Nemzeti Tankönyvkiadó, Budapest. 285 p.

BÁRDOS, J. 2006. Módszertan vagy nyelvpedagógia? In: THL2 (Teaching Hungarian as a 2nd Language and Hungarian Culture,1-2. sz. 5-14. p.

BEKÉNIOVÁ, L'. 2006. Hodnotenie v súčasnej škole. Progresívne trendy v školskom hodnotení. Prešov : MPC. 16 s. [online]. http:// www.mcpo.sk/downloads/Publikacie/Ostatne/OSRIA200702.pdf. [cit. 2015-06-10]

BENDÍKOVÁ, E. 2014. Lifestyle, physical and sports education and health benefits of physical activity. In European researcher : international multidisciplinary journal. Sochi : Academic publishing house Researcher, 2014. Vol. 69, no. 2-2, pp. 343-348. ISSN 2219-8229.

BENEDEK, A. 2015. Visuality as a tool for expanding learning. In: António Moreira Teixeira, András Szücs, ldikó Mázár (szerk.), 2015 Annual Conference. Barcelona : European Distance and E-Learning Network (EDEN), 2015. pp. 3-8. ISBN:978-6155511-03-5

BENEDEK, A. 2014. A vizualitás új lehetőségei a felnőttkori tanulásban. In: NEVELÉSTUDOMÁNY: OKTATÁS KUTATÁS INNOVÁCIÓ II:(1) pp. 21-29. 2014 
BERTRAND, Y. 1998. Soudobé teorie vzdělávání. Praha : Portál. 122 s. ISBN 80-7178-216-5.

BÓTA, M. 2005. Ostályozás nélküli értékelés és eredményesség. In BARÁTH, T., VÁRADY, E. 2005. Értékelés: a tanulás minősége a minőség tanulása. Szeged, Budapest : Qualitas T\&G Kft., Országos Közoktatási Intézet. s. 195-209. ISBN 963-682-564-5.

BUDA, A. 2013. Pedagógiai értékelés e-book. Értékelés az oktatásban. [online]. http://dragon.unideb.hu/ nevtud/Tanarkepzes/ meres/3_fejezet.pdf. 2013. [cit. 2015-10-10]

CANGELOSSI, J., S. 1994. Strategie řízení třídy. Jak získat a udržte spolupráci žáku při výuce. Praha : Portál. 289 s. ISBN 80-7178083-9

DYTRTOVÁ, R., KRHUTOVÁ, M. 2009. Učitel. Př́iprava na profesi. Praha : Grada. 128 s. ISBN 978-80-247-2863-6

GAVORA, P. 1999. Akí sú moji žiaci? Pedagogická diagnostika žiaka. Práca : Bratislava. 239 s. ISBN 80-7094-335-1

GAVORA, P. 2003. Učitel' a žiaci v komunikácii. Bratislava : UK. 197 s. ISBN 80-223-1716-0.

GOLNHOFER, E. 1993. Értékelés az iskolában. In GOLNHOFER, E., M. NÁDASI, M., SZABÓ, É. 1993. Készülünk a vizsgáztatásra. Budapest : Korona Kiadó. PSZM Projekt. s. 55-57.

GOLNHOFER, E. 2003. Pedagógiai értékelés. In FALUS, I. 2003. Didaktika. Budapest : Nemzeti Tankönyvkiadó. s. 385-417. ISBN 978-963-19-5296-4

HLÁSNA, S. 2008. Hodnotenie sociálnej klímy triedy žiakmi druhého stupňa ZŠ. In Výchova v pedagogickom výskume a praxi. Trnava : Filozofická fakulta, Univerzita sv. Cyrila a Metoda, s. 136-145. [online]. http://www.rcm.sk/data/galleries/13/2008_v8chova_v_ pedagogickom_v8skume_a praxi.pdf. [cit. 2015-09-18]

HORVÁTHOVÁ, K.- SZÖKÖL, I. 2013. Kontrola a hodnotenie žiackych výkonov $\mathrm{v}$ národnostných školách na Slovensku. Monographiae Comaromienses 9., Komárno: Univerzita J. Selyeho, 2013, 120. p., ISBN 978-80-8122-083-8. 
HORVÁTHOVÁ, K., MANNIOVÁ, J. 2008. Úvod do školského manažmentu. Ivánka pri Dunaji : AXIMA. 179 s. ISBN 978-80969178-6-0.

HRMO, R. - TUREK, I. 2003. Kl'účové kompetencie I. Bratislava: STU Bratislava, 2003. ISBN 80-227-1881-5.

HUPKOVÁ, M., PETLÁK, E. 2004. Sebareflexia a kompetencie v práci učitel'a. Bratislava : Iris. $135 \mathrm{~s}$. ISBN 80-89018-77-7.

Chráska, M. 1988. Didaktické testy v práci učitele. Olomouc : Krajský pedagogický ústav. $188 \mathrm{~s}$.

JANCSÁK, Cs. 2013. Ifjúsági korosztályok korszakváltásban. Budapest: Új Mandátum ISBN 9789632870649

KAŠIAROVÁ, N. 2009. Plánovanie kritérií a spôsobov hodnotenia vzdelávacích výstupov v predmete slovenský jazyk a literatúra $\mathrm{v}$ školskom vzdelávacom programe. Pedagogické rozhl'ady. Roč. 18, c. 5/2009, s. 4- 8. ISSN 1335-0404.

KOLÁŘ, Z., ŠIKULOVÁ, R. 2009. Hodnocení žáků. Praha : Grada Publishing. 200 s. ISBN 978-80-247-2834-6.

KOLÁŘ, Z., VALIŠOVÁ, A. 2009. Analýza vyučování. Praha : Grada Publishing. 232 s. ISBN 978-80-247-2857-5.

KOSOVÁ, B. 1998. Humanizačné premeny výchovy a vzdelávania na 1. stupni ZŠ. Banská Bystrica : MC. 88 s. ISBN 9788080412302. KOSOVÁ, B. 1997. Hodnotenie ako prostriedok humanizácie školy. 1. vyd. Banská Bystrica : PF UMB. 96 s. ISBN 80-8055-067-0.

KOSTRUB, D. 2008. Diet'a/žiak/študent - učivo - učitel', didaktický alebo bermudský trojuholník? Prešov : Rokus. 169 s. ISBN 97880-89055-87-6.

KOVÁCS, ZS. 2006. Az önszabályozó tanulás fejlesztésének lehetőségei. In Pedagógusképzés, 2006/3-4, s. 51-63. ISSN 0133-2570 KRELOVÁ, K. 2005. Pohl'ad učitel'ov na skúšanie a hodnotenie žiakov. [online]. http://www.mtf.stuba.sk/docs//internetovy_ casopis/2005/3/krelova.pdf. [cit. 2015-11-25]

LAPITKA, M. a kol. 2009. Didaktické základy novej koncepcie vyučovania literatúry a štruktúry učebníc na strednej škole. 
Bratislava : MPC. 67 s. [online]. http://www.mpc-edu.sk/library/ files/marian_lapitka_po_korekture_18_tlac.pdf. [cit. 2015-11-25] LAPPINTS, Á. 2002. Tanuláspedagógia. (A tanulás tanításának alapjai). Pécs : Comenius BT. 310 s. ISBN 963-009-046-5

MANNIOVÁ, J. 2008. Učitel' v procese výchovy a vzt'ahov. Ivánka pri Dunaji : AXIMA. 197 s. ISBN 978-80-969178-5-3.

OBDRŽÁLEK, Z. 1996. Škola, školský systém, ich organizácia a riadenie. Bratislava : UK. 220 s. ISBN 80-223-1035-2.

OBDRŽÁLEK, Z. et all. 2003. Didaktika pre študentov učitel'stva základnej školy. Bratislava : UK. 179 s. ISBN 9788022317726.

OBDRŽÁLEK, Z., HORVÁTHOVÁ, K. a kol. 2004. Organizácia a manažment školstva. Terminologický a výkladový slovník. Bratislava : SPN. 419 s. ISBN 80-10-00022-1.

PETLÁK, E. 1997. Všeobecná didaktika. Bratislava : Iris. $311 \mathrm{~s}$. ISBN80-88778-49-2.

PETLÁK, E.2004. Všeobecná didaktika. Bratislava : IRIS, 2004. 311

s. ISBN 80-89018-64-5.

PETTY, G. 1996. Moderní vyučování. Praha : Portál. 380 s. ISBN 80-7178-070-7.

PORUBSKÝ, Š. 2000. Prezentácia o rozvíjajúcom hodnotení. Žiar nad Hronom : Nadácia Škola dokorán

PRŮCHA, J. 1997. Moderní pedagogika. Praha : Portál. 480 s. ISBN 80-7178-170-3.

PUSKÁS, A. 2015. History of English Literature I. : a textbook for university students of English as a foreign language - 1. vyd. Komárno : Univerzita J. Selyeho, 2015. 113 s. ISBN 978-808122-137-8.

PUSKÁS, A. 2014. Female Identity in Feminist Adaptations of Shakespeare . 1. vyd. Budapest : Tinta, 2014. 134 s. ISBN 978615-5219-74-0.

SEDLÁK, M. et all. 1998. Manažment. Bratislava : Ekonomická univerzita. 256 s. ISBN 80-225-0909-4 
SETÉNYI J. 1999. A minőség kora. Budapest: Raabe Klett Könyvkiadó Kft., 1999, 228.p. ISBN 963-9194-27-1

SLAVÍK, J. 1999. Hodnocení v současné škole. Východiska a nové metody pro praxi. Praha : Portál. 192 s. ISBN 80-7178-262-9.

SRŠNÍKOVÁ, D. 2011. Vplyv spätnej väzby na komunikatívnu a lingvistickú úroveň zručnosti písania $\mathrm{v}$ anglickom jazyku. Dizertačná práca. Brno : MU, Filozofická fakulta. $196 \mathrm{~s}$.

SZARKA, K.-BRESTENSKÁ, B. 2015. Nové prostriedky hodnotenia procesu vzdelávania študentov vo vyučovaní chémie. In: Aktuálne trendy vo vyučovaní prírodných vied: Zborník z medzinárodnej konferencie. Trnava : Pedagogická fakulta Trnavskej Univerzity v Trnave, S. 362-367. ISBN 978-80-8082-541-6.

SZARKA, K. - BRESTENSKÁ, B. - JUHÁSZ, Gy. 2015. Analýza aspektov hodnotenia autentických výstupov a komplexného monitorovania žiackych prác $\mathrm{v}$ chémii. In: Didaktika chemie a její kontexty: 24. Mezinárodní konference o výuce chemie. Brno: Masarykova univerzita, 2015, CD-ROM, p. 200-208. ISBN 97880-210-7954-0.

SZÖKÖL, Š. 2010. Kl'účové kompetencie vo vzdelávaní pedagógov. In DRTINA, R., KOTKOVÁ, M. 2010. Modernizace vysokoškolské výuky technických predmetu. Hradec Králové : Nakladatelství Gaudeamus. s. 164-166. ISBN 978-80-7435-014-6.

SZÖKÖL, Š. - ALBERT, S. 2009. Prieskum hodnotovej orientácie pedagógov. In Chráska, M. - Klement, M. - Serafin, Č. -Havelka, M. (eds.): Trendy ve vzdelávání 2009: Dil I. Olomouc : Univerzita Palackého, 2009. 14-17 s. ISBN 978-80-7220-316-1

SZÖKÖL, I., HORVÁTHOVÁ, K. 2013. Kvalita vzdelávania z hl'adiska rozvoja informačných a komunikačných kompetencií učitel'a. In NEUBAUER, J., HÁJKOVÁ, E. 2013. XXXI. International Coloquium the Management of Educational Process. Brno : Univerzita obrany, Fakulta ekonomiky a managementu. s. 241245. ISBN 978-80-7231-924-4. 
ŠIMČÁKOVÁ, Z., KONČOKOVÁ, E. 2000. Škola dokorán - pokus o inováciu výchovy a vzdelávania. 1. čast'. In Pedagogická revue, roč. 52, 2000, č. 5, s. 414-426; 2. čast'. In Pedagogická revue, roč. 53, 2001, č. 1, s. 17-33. ISSN 1335-1982.

ŠKODA, J., DOULÍK, P. 2011. Psychodidaktika. Praha : Grada. 178 s. ISBN 978-80-247-3341-8

ŠTULRAJTEROVÁ, M. 2008. Skúšanie ústneho prejavu v cudzom jazyku. Banská Bystrica : UMB PdF. 103 s. ISBN 978-80-8083636-8.

ŠVEC, Š. 2005. Základné pojmy v pedagogike a andragogike. Bratislava : Iris. 318 s. ISBN 8089018319.

TINÁKOVÁ, T. 2007. Súčasné trendy v hodnotení. [online]. http:// www.mtf.stuba.sk/docs//internetovy_casopis/2007/2/tinakova2. pdf. [cit. 2015-11-25]

TÓTHOVÁ, R. 2001. Individuálna koncepcia vyučovania učitel'ov chémie a fyziky zist'ovaná Q-metodológiou. Aktuální otázky výuky chemie $X$. Sborník přednášek : mezinárodní konference o výuce chemie. Hradec Králové : Gaudeamus. s. 100-104. ISBN 9788070413043.

TUREK, I. 1996. Učitel' a didaktické testy. Bratislava : MCMB. 78 s. ISBN 9788071641391.

TUREK, I. 2008. Didaktika. Bratislava : Iura Edition. 595 s. ISBN 978-80-8078-198-9.

UHEREKOVÁ, M. 2008. Spätná väzba v školskom manažmente. Konferencia Školský manažment a príprava manažérov na jeho realizáciu ako faktory reformy školy 21.-22.1.2008 v Nitre. In Technológia vzdelávania. ročník XVI. č. 1/2008. Príloha Technológie vzdelávania Slovenský učitel' s. 11-14. ISSN 1335-1202

UHEREKOVÁ, M. 2009. Edukačný manažment a jeho miesto v školskom manažmente. Technológia vzdelávania. Roč. 17, č. 9/2009. s. 10-15. ISSN 1335-1202

VARGA, L. 2015. Új tudomány születőben: kisgyermekkori neuropedagógia. In: György Juhász, Ádám Nagy, Terézia Strédl, 
Anita Tóth-Bakos (szerk.) A Selye János Egyetem 2015-ös “Innováció és kreativitás az oktatásban és a tudományban" Nemzetközi Tudományos Konferenciájának tanulmánykötete. Komárno, SR, Univerzita J. Selyeho, 2015. s.11-18. ISBN 978-80-8122-144-6 VARGA, L. 2013. Az első évek örökké tartanak. In: Kurucz Rózsa (szerk.) Hidak és párhuzamok a 175 éves közép-európai és magyarországi óvóképzés történetében: konferencia. 355 p., Pécsi Tudományegyetem Illyés Gyula Kar, Szekszárd : HU, 2013. s.158-169. ISBN 9789637305658

VASS, V. 2015). Creative School: Renewing Leadership for Creativity. In. Tadeusz Marek, Waldemar Karwowski, Marek Frankowicz, Jussi Kantola, Pavel Zgaga (eds.): Human Factors of a Global Society: A System of Systems Perspective. Education in Modern Society. CRC Press, Taylor and Francis Group. Florida, US. 969-974.

VESELOVSKÁ, V. 2010. Hodnotenie a sebahodnotenie žiakov stredných škôl. [online]. http://www.kpsv.fsvaz.ukf.sk/PhD\%20 konf\%202010/SUBORY/PDF/06_Veselovska.pdf . [cit. 2015-1222]

ZELINA, M. 2009. Riadenie - jedna z klúčových oblastí reformy školy. Manažment školy v praxi. 1/2009. s. 1. 


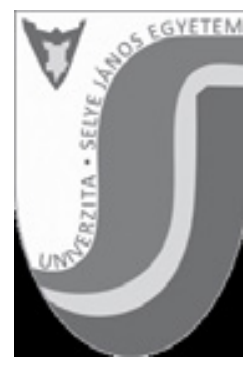

Univerzita J. Selyeho

Pedagogická fakulta

Bratislavská cesta 3322

SK-945 01 Komárno

www.ujs.sk

Szőköl István

Educational Evaluation in Contemporary Schools

Recenzensek:

Prof. Dr. Jenő Bárdos, DSc.

Dr. h.c. Prof. Ing. Albert Sándor, PhD.

Első kiadás

Nyomdai előkészítés: Szuperák Attila Nyomda: A-Szinvonal Nyomda, Szeged

Példányszám: 200

Kiadó: Belvedere Meridionale, Szeged

Szőköl István

Educational Evaluation in Contemporary Schools

Recenzenti / Reviewed by:

Prof. Dr. Jenő Bárdos, DSc.

Dr. h.c. Prof. Ing. Albert Sándor, PhD.

Prvé vydanie / First edition

Tlačová príprava / Typography:

Attila szuperák

Tlač / Press:

A-Szinvonal Nyomda, Szeged

Počet výtlačkov / Print run: 200

Vydavatel' / Publisher:

Belvedere Meridionale, Szeged

ISBN 978-615-5372-60-5 (print)

ISBN 978-615-5372-61-2 (online pdf) 


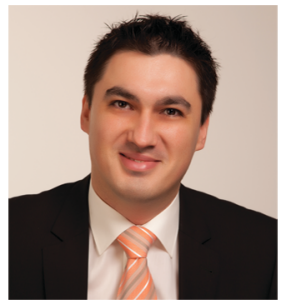

Completing his studies in 2004 at the Faculty of Material Science and Technology of the Slovak University of Technology in Bratislava, he specialised in industrial engineering and engineering management.

At the same time he supplemented his qualification with educational studies at the Department of Pedagogy and Psychology of the Faculty of Material Science and Technology.

In 2009 he achieved his doctoral degree - „Doctor Philosophiae.” $\mathrm{PhD}$ at the Educational Theory Department of the Slovak University of Technology in Bratislava.

From 2009 to 2012 he is the head of the Pre-school and Elementary Education Department of the Faculty of Education at the J. Selye University and from 2012 he is in charge of development and external relations as the Vice - Dean of the Faculty of Education.

In 2016 at the Eszterhazy Karoly University of Applied Sciences he successfully completed his Habilitation in the education research field. To this day, he has over 70 publications in national and international conferences on various topics, such as ICT use in the teaching process, the introduction of modular teaching in the education process, introducing the educational quality management, pedagogical communication and he is also the author and co-author of three lecture notes and three monographs.

Since 2011 he is the head of the Methodology and Pedagogy Centre for Komarno, where his main task is to provide supplementary trainings for Hungarian teachers.

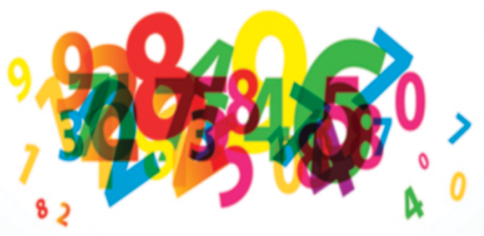

